\title{
Monetary and Macroprudential Policy in an Estimated DSGE Model of the Euro Area*
}

\author{
Dominic Quint ${ }^{\mathrm{a}}$ and Pau Rabanal ${ }^{\mathrm{b}}$ \\ ${ }^{a}$ Free University Berlin \\ ${ }^{\mathrm{b}}$ International Monetary Fund
}

\begin{abstract}
In this paper, we study the optimal mix of monetary and macroprudential policies in an estimated two-country model of the euro area. The model includes real, nominal, and financial frictions, and hence both monetary and macroprudential policy can play a role. We find that the introduction of a macroprudential rule would help reduce macroeconomic volatility, improve welfare, and partially substitute for the lack of national monetary policies. Macroprudential policy would always increase the welfare of savers, but its effects on borrowers depend on the shock that hits the economy. In particular, macroprudential policy may entail welfare costs for borrowers under technology shocks, by increasing the countercyclical behavior of lending spreads.
\end{abstract}

JEL Codes: C51, E44, E52.

\section{Introduction}

The recent financial crisis, which started in the summer of 2007, led to the worst recession since World War II. Before the crisis, a combination of loose monetary and regulatory policies encouraged

\footnotetext{
${ }^{*}$ Copyright (C) 2014 International Monetary Fund. We thank Pierpaolo Benigno, Helge Berger, Larry Christiano, Chris Erceg, Ivo Krznar, Vivien Lewis, Jesper Lindé, Olivier Loisel, Stephen Murchinson, Jorge Roldós, Thierry Tressel, and participants at various conferences and seminars for useful comments and discussions. This paper should not be reported as reflecting the views of the International Monetary Fund. Any errors and omissions are our own. Additional material on the derivation of the model and estimation results can be found at www.paurabanal.net/research.html. Author contact: Quint: Free University Berlin, Boltzmannstr. 20, 14195 Berlin, Germany, dominic.quint@fu-berlin.de. Rabanal: International Monetary Fund, 700 19th Street, N.W., Washington, D.C. 20431, prabanal@imf.org.
} 
excessive credit growth and a housing boom in many countries. This turned out to be a problem when the world economy slowed down: as Claessens, Kose, and Terrones (2009), Crowe et al. (2011), and International Monetary Fund (IMF) (2012) show, the combination of credit- and housing-boom episodes amplifies the business cycle and, in particular, the bust side of the cycle (measured as the amplitude and duration of recessions). Excessive leverage has complicated the recovery and the return to pre-crisis growth rates in several advanced countries - in particular, in the group of peripheral European countries known as GIIPS (Greece, Ireland, Italy, Portugal, and Spain). Developments in those countries since the launch of the European Economic and Monetary Union (EMU) in 1999 shared many characteristics with the run-up to other crises. Real exchange rate appreciation (which in the EMU took the form of persistent inflation differentials), large capital inflows mirrored by large current account deficits, and above-potential GDP growth rates fueled by cheap credit as well as asset-price bubbles are the traditional symptoms of ensuing financial, banking, and balance-of-payments crises in emerging and developed economies alike 11 In addition to all these overheating symptoms, the GIIPS countries faced prolonged negative real interest rates, which magnified the boom side of the business cycle. When the crisis hit, all problems came at once: a sudden stop of capital flows, concerns about debt sustainability, low or negative real GDP growth, and increased credit spreads that helped to amplify the bust side of the business cycle.

There is an increasing consensus that the best way to avoid a large recession in the future is precisely to reduce the volatility of credit cycles and their effects on the broader macroeconomy 2 However, the search for the appropriate toolkit to deal with financial and housing cycles is still in its infancy. There is high uncertainty on which measures can be more effective at delivering results. Conventional monetary policy is too blunt of an instrument to address imbalances within the financial sector or overheating in one sector of the economy (such as housing). There is a need to further strengthen other instruments of economic policy in dealing with sector-specific

\footnotetext{
${ }^{1}$ See Kaminsky and Reinhart (1999) and IMF (2009).

${ }^{2}$ See Galati and Moessner (2013) and the references therein.
} 
fluctuations 3 In particular, a key question to be addressed is the role of macroprudential regulation. Should it be used as a countercyclical policy tool, leaning against the wind of large credit, assetand house-price fluctuations, or should it take a more passive role and just aim at increasing the buffers of the banking system (provisions and capital requirements), thereby minimizing financial-sector risk, as currently envisioned in Basel III?

Our paper contributes to this debate by studying the optimal policy mix needed within a currency union, where country- and sectorspecific boom and bust cycles cannot be directly addressed with monetary policy. Specifically, we focus on the case of the EMU, where the European Central Bank (ECB) has the mandate of price stability at the union-wide level. Before the crisis, the GIIPS countries were not able to use monetary policy to cool down their economies and financial systems, or to address asset- and house-price bubbles or abnormal credit growth. Therefore, the use of other policy instruments in a currency union can potentially help in stabilizing the business and financial cycle. We provide a quantitative study on how monetary and macroprudential measures could interact in the euro area.

Early contributions to the debate on the role of macroprudential policies include several quantitative studies conducted by the Bank for International Settlements (BIS) on the costs and benefits of adopting the new regulatory standards of Basel III (see Macroeconomic Assessment Group (MAG) 2010a, 2010b, and Angelini et al. 2011), and in other policy institutions (see Bean et al. 2010, and Roger and Vlcek 2011). Other authors have also suggested that the use of macroprudential tools could improve welfare by providing instruments that target large fluctuations in credit markets. In an international real business-cycle model with financial frictions, Gruss and Sgherri (2009) study the role of loan-to-value (LTV) limits in reducing credit-cycle volatility in a small open economy with borrowing constraints. Bianchi and Mendoza (2011) analyze the effectiveness of macroprudential taxes to avoid the externalities associated with "overborrowing." Borio and Shim (2008) point out the prerequisite of a sound financial system for an effective monetary

\footnotetext{
${ }^{3}$ See Blanchard, Dell'Ariccia, and Mauro (2010).
} 
policy and, thus, the need to strengthen the interaction of prudential and monetary policy 4

Our paper fits in the recent (and growing) literature that embeds financial frictions in a dynamic stochastic general equilibrium (DSGE) model and searches for optimal monetary and macroprudential policy rules. Closest to our contribution are the papers by Brzoza-Brzezina, Kolasa, and Makarski (2013) and Rubio (2013), who also study the role of macroprudential policies in a two-country currency area but calibrate instead of estimate the model, as we do in this paper. Angelini, Neri, and Panetta (2011) and Beau, Clerc, and Mojon (2012) analyze macroprudential policies in an estimated DSGE model of the euro area but do not distinguish between different countries in the union. In these four cases, the credit friction consists in a borrowing constraint à la Iacoviello (2005), and hence there is no default. Lambertini, Mendicino, and Punzi (2013) study the effect of LTV ratios on welfare in a calibrated closed-economy model with housing and risky mortgages, which is similar to our setup for the financial friction. Other contributions of DSGE models with a financial accelerator include Unsal (2013) and Medina and Roldós (2014), who study the role of macroprudential policy when a small open emerging economy receives large capital inflows. A common result in this literature is that the optimal macroprudential policy is state dependent, and, therefore, simple operational rules that react to observable variables may lead to policy mistakes. For instance, if the source of a credit boom is a productivity shock, and the macroprudential authority reacts mechanically to a credit variable (rather than to the effects of the shock), then welfare might decrease.

In all these previous contributions, and in the present paper, macroprudential policies aim at reducing the volatility effects of a built-in financial accelerator but do not affect the risk-taking behavior of agents. An important exception to the literature is the paper by Collard et al. (2013), which includes risky technologies in a DSGE model and studies how macroprudential policies can reduce risk-taking behavior. In Collard et al. (2013), firms can use

\footnotetext{
${ }^{4}$ Bank of England (2009) lists several reasons why the short-term interest rate may be ill suited and should be supported by other measures to combat financial imbalances.
} 
either a riskless or a risky technology to produce capital goods. The risky technology is socially inefficient because it delivers, in expected value, a lower return than the riskless technology. However, limited liability and deposit insurance provides an incentive to "gamble" and collect the profits when the risky technology delivers a high payoff. In their model, monetary policy can only affect the quantity but not the composition of credit. The optimal macroprudential policy sets the capital requirement to a sufficiently high level, such that firms internalize the riskiness of their choices and only adopt the riskless, socially optimal technology. Hence, the optimal capital asset ratio moves with shocks that affect risk in the economy (such as the return of the risky technology), but it stays constant when shocks do not affect risk (such as an economy-wide productivity shock).

In this paper, we quantify the role of monetary and macroprudential policies in stabilizing the business cycle in the euro area using an estimated DSGE model. The model includes (i) two countries (a core and a periphery) which share the same currency and monetary policy; (ii) two sectors (non-durables and durables, which can be thought of as housing); and (iii) two types of agents (savers and borrowers) such that there is a credit market in each country and across countries in the monetary union. The model also includes a financial accelerator mechanism on the household side, such that changes in the balance sheet of borrowers due to house-price fluctuations affect the spread between lending and deposit rates. In addition, risk shocks in the housing sector affect conditions in the credit markets and in the broader macroeconomy. The model is estimated using Bayesian methods and includes several nominal and real rigidities to fit the data, as in Smets and Wouters (2003) and Iacoviello and Neri (2010).

Basel III calls for regulators to step in when there is excessive credit growth in the economy 5 We want to study the pros and cons of reacting to credit indicators, by using either monetary or macroprudential policies. Having obtained estimates for the parameters of the model and for the exogenous shock processes, we proceed to study different policy regimes. In all cases, we assume that the optimal policy aims at maximizing the welfare of all households in the

\footnotetext{
${ }^{5}$ See Basel Committee on Banking Supervision (2011).
} 
EMU by maximizing their utility function, taking into account the population weights of each type of household in each country. First, we derive the optimal monetary policy when the ECB optimizes over the coefficients of the Taylor rule that reacts to EMU-wide consumer price index (CPI) inflation and real output growth. We find that the optimal Taylor rule strongly reacts to deviations of CPI inflation and output growth from their steady-state values, as is typical in the literature. Afterwards, we extend the monetary policy rule to react to credit aggregates. We find that the extended Taylor rule improves welfare with respect to the original one, with borrowers being worse off under some conditions.

Next, we introduce a macroprudential instrument that influences credit market conditions above and beyond current regulations. This instrument targets credit spreads by affecting the fraction of liabilities (deposits and bonds) that financial intermediaries can lend. Spreads can be increased by imposing, e.g., additional capital surcharges, liquidity ratios, loan-loss provisions, or reserve requirements, whereas the direct provision of liquidity to the banking sector (either through conventional or unconventional policies) can decrease spreads 6 This could be achieved via measures such as widening of collateral standards, the Funding for Lending Scheme launched by the Bank of England in 2012, or even liquidity provision to the real economy as in Gertler and Karadi (2011). We find that by introducing macroprudential policies, welfare further increases, but there are winners and losers as a result of including these measures. As we discuss in section 4, optimal monetary and macroprudential policies are welfare improving under housing demand or risk shocks: these measures reduce the volatility of real variables by offsetting accelerator effects triggered by these shocks. However, when technology shocks hit the economy, macroprudential policies have the opposite effect and magnify the countercyclical behavior of the lending-deposit spread. This imposes larger fluctuations of consumption, housing investment, and hours worked for borrowers and, thus, reduces their welfare. Therefore, identifying the source of the credit and house-price boom is crucial for the success of policy measures that react to financial variables.

\footnotetext{
${ }^{6}$ See Crowe et al. (2011) and Vandenbussche, Vogel, and Detragiache (2012) for a discussion on the effects of different macroprudential measures.
} 
The rest of the paper is organized as follows: section 2 presents the model and section 3 discusses the data as well as the econometric methodology to estimate the parameters of the model. In section 4 , we discuss the different exercises of optimal monetary and macroprudential policies, while we leave section 5 for concluding remarks.

\section{The Model}

The theoretical framework consists of a two-country, two-sector, twoagent general equilibrium model of a single currency area. The two countries, home and foreign, are of size $n$ and $1-n$. There are two types of goods, durables and non-durables, that are produced under monopolistic competition and nominal rigidities. While non-durables are traded across countries, durable goods are non-tradable. In each country, there are two types of agents, savers ( $\operatorname{size} \lambda$ in each country) and borrowers $(1-\lambda)$, who differ in their discount factor and habit formation parameter. Both agents consume non-durable goods and purchase durable goods to increase their housing stock. Borrowers are more impatient than savers and have a preference for early consumption, which creates the condition for credit to occur in equilibrium. In addition, borrowers are hit by an idiosyncratic quality shock to their housing stock, which affects the value of collateral that they can use to borrow against 7 Hence, we adapt the mechanism of Bernanke, Gertler, and Gilchrist (1999), henceforth BGG, to the household side and to residential investment: shocks to the valuation of housing affect the balance sheets of borrowers, which in turn affect the default rate on mortgages and the lending-deposit spread.

There are two types of financial intermediaries. Domestic financial intermediaries take deposits from savers, grant loans to borrowers, and issue bonds. International financial intermediaries trade these bonds across countries to channel funds from one country to the other. Therefore, savings and (residential) investment need not be balanced at the country level period by period, since excess credit

\footnotetext{
${ }^{7}$ We could also assume that savers are hit by a housing quality shock. Since they do not borrow and use their housing stock as collateral, this quality shock would not have any macroeconomic impact.
} 
demand in one region can be met by funding coming from elsewhere in the monetary union. In compensation for this service, international financial intermediaries charge a risk premium which depends on the net foreign asset position of the country.

In what follows, we only present the home country block of the model, by describing the domestic and international credit markets, households, and firms. Monetary policy is conducted by a central bank that targets the union-wide CPI inflation rate, and also reacts to fluctuations in the union-wide real GDP growth. Because the foreign country block is characterized by a similar structure regarding credit markets, households, and firms, we refrain from presenting it. Unless specified, all shocks follow zero-mean $\mathrm{AR}(1)$ processes in logs.

\subsection{Credit Markets}

We adapt the BGG financial accelerator idea to the housing market, by introducing default risk in the mortgage market, and a lending-deposit spread that depends on housing market conditions. There are two main differences with respect to the BGG mechanism. First, there are no agency problems or asymmetric information in the model, and borrowers will only default if they find themselves underwater - that is, when the value of their outstanding debt is higher than the value of the house they own. Second, unlike the BGG setup, we assume that the one-period lending rate is pre-determined and does not depend on the state of the economy, which seems to be a more realistic assumption 8

\subsubsection{Domestic Intermediaries and Macroprudential Policy}

Domestic financial intermediaries collect deposits from savers $S_{t}$, for which they pay a deposit rate $R_{t}$, and extend loans to borrowers $S_{t}^{B}$, for which they charge the lending rate $R_{t}^{L}$. Credit granted to borrowers is backed by the value of the housing stock that they own $\left(P_{t}^{D} D_{t}^{B}\right)$, where $P_{t}^{D}$ is the nominal house price and $D_{t}^{B}$ is the housing stock owned by borrowers. We introduce risk in the credit and housing markets by assuming that each borrower (indexed by

${ }^{8}$ A similar approach is taken by Zhang (2009) and Suh (2012). 
$j$ ) is subject to an idiosyncratic quality shock to the value of her housing stock, $\omega_{t}^{j}$, that is log-normally distributed with cumulative distribution function $F(\omega)$. We choose the mean and standard deviation so that $E \omega_{t}=1$ and, hence, there is idiosyncratic risk but not aggregate risk in the housing market. This assumption implies that $\log \left(\omega_{t}^{j}\right) \sim N\left(-\frac{\sigma_{\omega, t}^{2}}{2}, \sigma_{\omega, t}^{2}\right)$, with $\sigma_{\omega, t}$ being the standard deviation characterizing the quality shock. This standard deviation is time varying and follows an $\mathrm{AR}(1)$ process in logs:

$$
\log \left(\sigma_{\omega, t}\right)=\left(1-\rho_{\sigma_{\omega}}\right) \log \left(\bar{\sigma}_{\omega}\right)+\rho_{\sigma_{\omega}} \log \left(\sigma_{\omega, t-1}\right)+u_{\omega, t}
$$

with $u_{\omega, t} \sim N\left(0, \sigma_{u_{\omega}}\right)$.

The quality shock $\omega_{t}^{j}$ can lead to mortgage defaults and affects the spread between lending and deposit rates. The realization of the shock is known at the end of the period. High realizations of $\omega_{t-1}^{j}$ allow households to repay their loans in full, and hence they repay the full amount of their outstanding loan $R_{t-1}^{L} S_{t-1}^{B}$. Realizations of $\omega_{t-1}^{j}$ that are low enough make households default on their loans in period $t$. After the household defaults on its loan, the bank calls a debt-collection agency that forces the household to repay the value of the housing stock after the shock has realized, $\omega_{t-1}^{j} P_{t}^{D} D_{t}^{B}$. After paying this amount, the household keeps its house. These debt-collection agencies charge banks a fraction $\mu$ of the value of the house. The profits of these agencies are transferred to savers, who own them. The value of the idiosyncratic shock is common knowledge, so households will only default when they are underwater 9

When granting credit, financial intermediaries do not know the threshold $\bar{\omega}_{t}$ which defines the cut-off value of those households that default and those that do not. The ex ante threshold value expected by banks is thus given by

$$
\bar{\omega}_{t}^{a} E_{t}\left[P_{t+1}^{D} D_{t+1}^{B}\right]=R_{t}^{L} S_{t}^{B} .
$$

\footnotetext{
${ }^{9}$ Under this assumption, no fraction of the housing stock is destroyed during the foreclosure process. If, as in BGG, a fraction of the collateral was lost during foreclosure, risk shocks might have unrealistic expansionary effects on housing and residential investment. See Forlati and Lambertini (2011).
} 
Intermediaries behave in a risk-neutral way and require the expected return from granting one euro of credit to be equal to the funding rate of banks, which equals the deposit rate $\left(R_{t}\right)$ :

$$
\begin{aligned}
R_{t} & =E_{t}\left\{(1-\mu) \int_{0}^{\bar{\omega}_{t}^{a}} \omega d F\left(\omega, \sigma_{\omega, t}\right) \frac{P_{t+1}^{D} D_{t+1}^{B}}{S_{t}^{B}}+\left[1-F\left(\bar{\omega}_{t}^{a}, \sigma_{\omega, t}\right)\right] R_{t}^{L}\right\} \\
& =E_{t}\left\{(1-\mu) G\left(\bar{\omega}_{t}^{a}, \sigma_{\omega, t}\right) \frac{P_{t+1}^{D} D_{t+1}^{B}}{S_{t}^{B}}+\left[1-F\left(\bar{\omega}_{t}^{a}, \sigma_{\omega, t}\right)\right] R_{t}^{L}\right\},
\end{aligned}
$$

with $\left[1-F\left(\bar{\omega}_{t}^{a}, \sigma_{\omega, t}\right)\right]=\int_{\bar{\omega}_{t}^{a}}^{\infty} d F\left(\omega ; \sigma_{\omega, t}\right) d \omega$ being the expected probability that the shock exceeds the ex ante threshold $\bar{\omega}_{t}^{a}$ and $G\left(\bar{\omega}_{t}^{a}, \sigma_{\omega, t}\right)=\int_{0}^{\bar{\omega}_{t}^{a}} \omega d F\left(\omega ; \sigma_{\omega, t}\right)$ being the expected value of the shock conditional on the shock being less than $\bar{\omega}_{t}^{a}$. The participation constraint (2) ensures that the opportunity costs $R_{t}$ are equal to the expected returns, which are given by the expected foreclosure settlement as a percentage of outstanding credit (the first term of the right-hand side of equation (2)) and the expected repayment of households with higher housing values (the second term). Due to the fees paid to debt-collection agencies to make defaulting households pay their debts, financial intermediaries only receive a fraction $(1-\mu)$ of the mortgage settlement.

We introduce the macroprudential instrument, denoted by $\eta_{t}$, that influences credit market conditions by affecting the fraction of liabilities that banks can lend. We discuss its properties in section 2.4.3. The aggregate balance sheet of domestic financial intermediaries in the home country is

$$
n \lambda \frac{1}{\eta_{t}}\left(S_{t}-B_{t}\right)=n(1-\lambda) S_{t}^{B}
$$

where $B_{t}$ are claims on financial intermediaries in the foreign country (as explained below). Combined with the participation constraint equation (2), we obtain the following relationship between the lending-deposit spread and macroprudential policy:

$$
\frac{R_{t}^{L}}{R_{t}}=E_{t}\left\{\frac{\eta_{t}}{\frac{(1-\mu) G\left(\bar{\omega}_{t}^{a}, \sigma_{\omega, t}\right)}{\bar{\omega}_{t}^{a}}+\left[1-F\left(\bar{\omega}_{t}^{a}, \sigma_{\omega, t}\right)\right]}\right\} .
$$


According to equation (4), for a given demand of credit from borrowers, observed values of risk $\sigma_{\omega, t}$, a stance of macroprudential policy $\eta_{t}$, and expected values of the housing stock $E_{t}\left[P_{t+1}^{D} D_{t+1}^{B}\right]$, intermediaries passively set the lending rate $R_{t}^{L}$ and the expected (ex ante) threshold $\bar{\omega}_{t}^{a}$ so that equation (1) and the participation constraint (2) are fulfilled. Unlike the original BGG setup, the oneperiod lending rate $R_{t}^{L}$ is determined at time $t$ and does not depend on the state of the economy at $t+1$. This means that the participation constraint of financial intermediaries delivers ex ante zero profits. However, it is possible that, ex post, they make profits or losses. We assume that savers collect profits or recapitalize financial intermediaries as needed.

It is worth emphasizing that the participation constraint delivers a positive relationship between LTV ratios $\left(S_{t}^{B} / P_{t+1}^{D} D_{t+1}^{B}\right)$ and the spread between the funding and the lending rate, due to the probability of default. Let's first assume that $\eta_{t}=\mu=1$ in equation (4), so there is no macroprudential regulation and, in the case of default, the financial intermediary recovers nothing from the defaulted loan. According to equation (1), the higher the LTV ratio, the higher the threshold $\bar{\omega}_{t}^{a}$ that leads to default. This shrinks the area of no default $\left[1-F\left(\bar{\omega}_{t}^{a}, \sigma_{\omega, t}\right)\right]$, and therefore increases the spread between $R_{t}^{L}$ and $R_{t}$. Similarly, an increase in the standard deviation $\sigma_{\omega, t}$ increases the spread between the lending and the deposit rates. When $\sigma_{\omega, t}$ rises, it leads to a mean-preserving spread for the distribution of $\omega_{t}^{j}$ : the tails of the distribution become fatter while the mean remains unchanged. As a result, lower realizations of $\omega_{t}^{j}$ are more likely so that more borrowers will default on their loans. More generally, when the financial intermediary is able to recover a fraction $(1-\mu)$ of the collateral value, it can be shown (using the properties of the lognormal distribution when $E \omega_{t}=1$ ) that the denominator in the spread equation (4) is always declining in $\bar{\omega}_{t}^{a}$, and hence the spread is always an increasing function of the LTV. Evidence for the euro area suggests that mortgage spreads are an increasing function of the LTV ratio, as discussed in Sørensen and Lichtenberger (2007) and ECB (2009).

Finally, we assume that the deposit rate in the home country equals the risk-free rate set by the central bank. In the foreign country, domestic financial intermediaries behave the same way. In their 
case, they face a deposit rate $R_{t}^{*}$ and a lending rate $R_{t}^{L^{*}}$, and the spread is determined in an analogous way to equation (2), including a macroprudential instrument $\eta_{t}^{*}$. We explain below how the deposit rate in the foreign country $R_{t}^{*}$ is determined.

\subsubsection{International Intermediaries}

International financial intermediaries buy and sell bonds issued by domestic intermediaries in both countries. For instance, if the home country domestic intermediaries have an excess $B_{t}$ of loanable funds, they will sell them to the international intermediaries, who will lend an amount $B_{t}^{*}$ to foreign country domestic intermediaries. International intermediaries apply the following formula to the spread they charge between bonds in the home country (issued at an interest rate $R_{t}$ ) and the foreign country (issued at $R_{t}^{*}$ ):

$$
R_{t}^{*}=R_{t}+\left\{\vartheta_{t} \exp \left[\kappa_{B}\left(\frac{B_{t}}{P_{t}^{C} Y^{C}}\right)\right]-1\right\} .
$$

The spread depends on the ratio of real net foreign assets $B_{t} / P_{t}^{C}$ to steady-state non-durable GDP $\left(Y^{C}\right)$ in the home country (to be defined below). When home country domestic intermediaries have an excess of funds that they wish to lend to the foreign country domestic intermediaries, then $B_{t}>0$. Hence, the foreign country intermediaries will pay a higher interest rate $R_{t}^{*}>R_{t}$. The parameter $\kappa_{B}$ denotes the risk premium elasticity and $\vartheta_{t}$ is a risk premium shock, which increases the wedge between the domestic and the foreign deposit rates. International intermediaries are owned by savers in each country, and optimality conditions will ensure that the net foreign asset position of both countries is stationary 10 They always make positive profits $\left(R_{t}^{*}-R_{t}\right) B_{t}$, which are equally split across savers of both countries.

\footnotetext{
${ }^{10}$ Hence, the assumption that international intermediaries trade uncontingent bonds amounts to the same case as allowing savers to trade these bonds. Under market incompleteness, a risk premium function of the type assumed in equation (5) is required for the existence of a well-defined steady state and stationarity of the net foreign asset position. See Schmitt-Grohé and Uribe (2003).
} 


\subsection{Households}

\subsubsection{Savers}

Savers indexed by $j \in[0, \lambda]$ maximize the following utility function:

$$
E_{0}\left\{\sum_{t=0}^{\infty} \beta^{t}\left[\gamma \xi_{t}^{C} \log \left(C_{t}^{j}-\varepsilon C_{t-1}\right)+(1-\gamma) \xi_{t}^{D} \log \left(D_{t}^{j}\right)-\frac{\left(L_{t}^{j}\right)^{1+\varphi}}{1+\varphi}\right]\right\}
$$

where $C_{t}^{j}, D_{t}^{j}$, and $L_{t}^{j}$ represent the consumption of the flow of non-durable goods, the stock of durable goods (housing), and the labor disutility of agent $j$. Following Smets and Wouters (2003) and Iacoviello and Neri (2010), we assume external habit persistence in non-durable consumption, with $\varepsilon$ measuring the influence of past aggregate non-durable consumption $C_{t-1}$. The utility function is hit by two preference shocks, affecting the marginal utility of either non-durable consumption $\left(\xi_{t}^{C}\right)$ or housing $\left(\xi_{t}^{D}\right)$. The parameter $\beta$ stands for the discount factor of savers, $\gamma$ measures the share of non-durable consumption in the utility function, and $\varphi$ denotes the inverse elasticity of labor supply. Moreover, non-durable consumption is an index composed of home $\left(C_{H, t}^{j}\right)$ and foreign $\left(C_{F, t}^{j}\right)$ goods:

$$
C_{t}^{j}=\left[\tau^{\frac{1}{\iota_{C}}}\left(C_{H, t}^{j}\right)^{\frac{\iota_{C}-1}{{ }^{{ }^{C} C}}}+(1-\tau)^{\frac{1}{\iota_{C}}}\left(C_{F, t}^{j}\right)^{\frac{\iota_{C}-1}{{ }^{C} C}}\right]^{\frac{\iota_{C}}{\iota_{C}-1}},
$$

with $\tau \in[0,1]$ denoting the fraction of domestically produced nondurables at home and $\iota_{C}$ governing the substitutability between domestic and foreign goods. Following Iacoviello and Neri (2010), we introduce imperfect substitutability of labor supply between the durable and non-durable sector to explain co-movement at the sector level:

$$
L_{t}^{j}=\left[\alpha^{-\iota_{L}}\left(L_{t}^{C, j}\right)^{1+\iota_{L}}+(1-\alpha)^{-\iota_{L}}\left(L_{t}^{D, j}\right)^{1+\iota_{L}}\right]^{\frac{1}{1+\iota_{L}}} .
$$

The labor disutility index consists of hours worked in the nondurable sector $L_{t}^{C, j}$ and durable sector $L_{t}^{D, j}$, with $\alpha$ denoting the 
share of employment in the non-durable sector. Reallocating labor across sectors is costly and is governed by the parameter $\iota_{L} 11$ Wages are flexible and set to equal the marginal rate of substitution between consumption and labor in each sector.

The budget constraint of savers in nominal terms reads as follows:

$$
P_{t}^{C} C_{t}^{j}+P_{t}^{D} I_{t}^{j}+S_{t}^{j} \leq R_{t-1} S_{t-1}^{j}+W_{t}^{C} L_{t}^{C, j}+W_{t}^{D} L_{t}^{D, j}+\Pi_{t}^{j},
$$

where $P_{t}^{C}$ and $P_{t}^{D}$ are the price indices of non-durable and durable goods, respectively, which are defined below. Nominal wages paid in the two sectors are denoted by $W_{t}^{C}$ and $W_{t}^{D}$. Savers allocate their expenditures between non-durable consumption $C_{t}^{j}$ and residential investment $I_{t}^{j}$. They have access to deposits in the domestic financial system $S_{t}^{j}$, which pay the deposit interest rate $R_{t}$. In addition, savers also receive profits $\Pi_{t}^{j}$ from intermediate goods producers in the durable and the non-durable sector, from domestic and international financial intermediaries, and from debt-collection agencies that charge fees to domestic financial intermediaries to make defaulting households pay their debts.

Purchases of durable goods, or residential investment $I_{t}^{j}$, are used to increase the housing stock $D_{t}^{j}$ with a lag, according to the following law of motion:

$$
D_{t}^{j}=(1-\delta) D_{t-1}^{j}+\left[1-\digamma\left(\frac{I_{t-1}^{j}}{I_{t-2}^{j}}\right)\right] I_{t-1}^{j},
$$

where $\delta$ denotes the depreciation rate of the housing stock and $\digamma(\cdot)$ an adjustment cost function. Following Christiano, Eichenbaum, and Evans (2005), $\digamma(\cdot)$ is a convex function, which in steady state meets the following criteria: $\bar{\digamma}=\bar{\digamma}^{\prime}=0$ and $\bar{\digamma}^{\prime \prime}>012$

\subsubsection{Borrowers}

Borrowers differ from savers along three main dimensions. First, their preferences are different. The discount factor of borrowers is

\footnotetext{
${ }^{11}$ Note that when $\iota_{L}=0$ the aggregator is linear in hours worked in each sector and there are no costs of switching between sectors.

${ }^{12}$ This cost function allows us to replicate hump-shaped responses of residential investment to shocks and reduce residential investment volatility.
} 
smaller than the respective factor of savers $\left(\beta^{B}<\beta\right)$, and we allow for different habit formation coefficients $\varepsilon^{B}$. Second, borrowers do not earn profits from intermediate goods producers, financial intermediaries, or debt-collection agencies. Finally, as discussed above, borrowers are subject to a quality shock to the value of their housing stock $\omega_{t}^{j}$. Since borrowers are more impatient, in equilibrium, savers are willing to accumulate assets as deposits, and borrowers are willing to pledge their housing wealth as collateral to gain access to loans. Analogously to savers, the utility function for each borrower $j \in[\lambda, 1]$ reads as follows:

$$
\begin{gathered}
E_{0}\left\{\sum _ { t = 0 } ^ { \infty } \beta ^ { B , t } \left[\gamma \xi_{t}^{C} \log \left(C_{t}^{B, j}-\varepsilon^{B} C_{t-1}^{B}\right)\right.\right. \\
\left.\left.+(1-\gamma) \xi_{t}^{D} \log \left(D_{t}^{B, j}\right)-\frac{\left(L_{t}^{B, j}\right)^{1+\varphi}}{1+\varphi}\right]\right\},
\end{gathered}
$$

where all variables and parameters with the superscript $B$ denote that they are specific to borrowers. The indices of consumption and hours worked, and the law of motion of the housing stock, have the same functional form as in the case of savers (equations (7), (8), and (10)). The budget constraint for borrowers differs among those who default and those who repay their loans in full. Hence, aggregating borrowers' budget constraints and dropping the $j$ superscripts, we obtain the following:

$$
\begin{aligned}
P_{t}^{C} C_{t}^{B} & +P_{t}^{D}\left[I_{t}^{B}+G\left(\bar{\omega}_{t-1}^{p}, \sigma_{\omega, t-1}\right) D_{t}^{B}\right] \\
& +\left[1-F\left(\bar{\omega}_{t-1}^{p}, \sigma_{\omega, t-1}\right)\right] R_{t-1}^{L} S_{t-1}^{B} \\
\leq & S_{t}^{B}+W_{t}^{C} L_{t}^{C, B}+W_{t}^{D} L_{t}^{D, B} .
\end{aligned}
$$

Borrowers consume non-durables $C_{t}^{B}$, invest in the housing stock $I_{t}^{B}$, and supply labor to both sectors $\left(L_{t}^{C, B}\right.$ and $\left.L_{t}^{D, B}\right)$. Savers and borrowers are paid the same wages $W_{t}^{C}$ and $W_{t}^{D}$ in both sectors. That is, hiring firms are not able to discriminate types of labor depending on whether a household is a saver or a borrower. Borrowers obtain loans $S_{t}^{B}$ from financial intermediaries at a lending 
rate $R_{t}^{L}$. After aggregate and idiosyncratic shocks hit the economy, borrowers will default if the realization of the idiosyncratic shock falls below the ex post threshold:

$$
\bar{\omega}_{t-1}^{p}=\frac{R_{t-1}^{L} S_{t-1}^{B}}{P_{t}^{D} D_{t}^{B}} .
$$

Since investment increases the housing stock with a lag (equation $(10)), D_{t}^{B}$ is a pre-determined variable. Because the lending rate is also pre-determined and is not a function of the state of the economy, it is possible that $\bar{\omega}_{t}^{a}$ and $\bar{\omega}_{t}^{p}$ differ. Note, however, that when the loan is signed, $\bar{\omega}_{t}^{a}=E_{t} \bar{\omega}_{t}^{p}$. The term $\left[1-F\left(\bar{\omega}_{t-1}^{p}, \sigma_{\omega, t-1}\right)\right]=$ $\int_{\bar{\omega}_{t-1}^{p}}^{\infty} d F\left(\omega ; \sigma_{\omega, t-1}\right) d \omega$ defines the fraction of loans that are repaid by the borrowers, because they were hit by a realization of the shock above the threshold $\bar{\omega}_{t-1}^{p}$. Similarly, $P_{t}^{D} G\left(\bar{\omega}_{t-1}^{p}, \sigma_{\omega, t-1}\right) D_{t}^{B}=$ $P_{t}^{D} \int_{0}^{\bar{\omega}_{t-1}^{p}} \omega d F\left(\omega ; \sigma_{\omega, t-1}\right) D_{t}^{B}$ is the value of the housing stock which borrowers have defaulted on and which is paid to banks after a debt-collection agency intervenes.

\subsection{Firms, Technology, and Nominal Rigidities}

In each country, homogeneous final non-durable and durable goods are produced using a continuum of intermediate goods in each sector (indexed by $h \in[0, n]$ in the home and by $f \in[n, 1]$ in the foreign country). Intermediate goods in each sector are imperfect substitutes of each other, and there is monopolistic competition as well as staggered price setting à la Calvo (1983). Intermediate goods are not traded across countries and are bought by domestic final goods producers. In the final goods sector, non-durables are sold to domestic and foreign households 13 Durable goods are solely sold to domestic households, who use them to increase the housing stock. Both final goods sectors are perfectly competitive, operating under flexible prices.

\footnotetext{
${ }^{13}$ Thus, for non-durable consumption we need to distinguish between the price level of domestically produced non-durable goods $P_{H, t}$, of non-durable goods produced abroad $P_{F, t}$, and the consumer price index $P_{t}^{C}$, which will be a combination of these two price levels.
} 


\subsubsection{Final Goods Producers}

Final goods producers in both sectors aggregate the intermediate goods they purchase according to the following production function:

$$
Y_{t}^{k} \equiv\left[\left(\frac{1}{n}\right)^{\frac{1}{\sigma_{k}}} \int_{0}^{n} Y_{t}^{k}(h)^{\frac{\sigma_{k}-1}{\sigma_{k}}} d h\right]^{\frac{\sigma_{k}}{\sigma_{k}-1}}, \text { for } k=\{C, D\},
$$

where $\sigma_{k}$ represents the price elasticity of intermediate goods. Profit maximization leads to the following demand function for individual intermediate goods:

$$
Y_{t}^{C}(h)=\left(\frac{P_{t}^{H}(h)}{P_{t}^{H}}\right)^{-\sigma_{C}} Y_{t}^{C} \text { and } Y_{t}^{D}(h)=\left(\frac{P_{t}^{D}(h)}{P_{t}^{D}}\right)^{-\sigma_{D}} Y_{t}^{D} .
$$

Price levels for domestically produced non-durables $\left(P_{t}^{H}\right)$ and durable final goods $\left(P_{t}^{D}\right)$ are obtained through the usual zero-profit condition:

$$
\begin{aligned}
P_{t}^{H} & \equiv\left\{\frac{1}{n} \int_{0}^{n}\left[P_{t}^{H}(h)\right]^{1-\sigma_{C}} d h\right\}^{\frac{1}{1-\sigma_{C}}} \text { and } \\
P_{t}^{D} & \equiv\left\{\frac{1}{n} \int_{0}^{n}\left[P_{t}^{D}(h)\right]^{1-\sigma_{D}} d h\right\}^{\frac{1}{1-\sigma_{D}}} .
\end{aligned}
$$

The price level for non-durables consumed in the home country (i.e., the CPI for the home country) includes the price of domestically produced non-durables $\left(P_{t}^{H}\right)$ and of imported non-durables $\left(P_{t}^{F}\right)$ :

$$
P_{t}^{C}=\left[\tau\left(P_{t}^{H}\right)^{1-\iota_{C}}+(1-\tau)\left(P_{t}^{F}\right)^{1-\iota_{C}}\right]^{\frac{1}{1-\iota_{C}}} .
$$

\subsubsection{Intermediate Goods Producers}

Intermediate goods are produced under monopolistic competition with producers facing staggered price setting in the spirit of Calvo (1983), which implies that in each period only a fraction $1-\theta_{C}(1-$ $\left.\theta_{D}\right)$ of intermediate goods producers in the non-durable (durable) sector receive a signal to reoptimize their price. For the remaining 
fraction $\theta_{C}\left(\theta_{D}\right)$, we assume that their prices are partially indexed to lagged sector-specific inflation (with a coefficient $\phi_{C}, \phi_{D}$ in each sector). In both sectors, intermediate goods are produced solely with labor:

$$
Y_{t}^{C}(h)=A_{t} Z_{t}^{C} L_{t}^{C}(h), \quad Y_{t}^{D}(h)=A_{t} Z_{t}^{D} L_{t}^{D}(h) \quad \text { for all } h \in[0, n] .
$$

The production functions include country- and sector-specific stationary technology shocks $Z_{t}^{C}$ and $Z_{t}^{D}$, each of which follows a zero-mean $\mathrm{AR}(1)$ process in logs. In addition, we introduce a nonstationary union-wide technology shock, which follows a unit-root process:

$$
\log \left(A_{t}\right)=\log \left(A_{t-1}\right)+\varepsilon_{t}^{A} .
$$

This shock introduces non-stationarity to the model and constitutes a model-consistent way of detrending the data by taking logs and first differences to the real variables that inherit the randomwalk behavior. In addition, it adds some correlation of technology shocks across sectors and countries, which is helpful from the empirical point of view because it allows us to explain co-movement of main real variables. Since labor is the only production input, cost minimization implies that real marginal costs in both sectors are given by

$$
M C_{t}^{C}=\frac{W_{t}^{C} / P_{H, t}}{A_{t} Z_{t}^{C}}, \quad M C_{t}^{D}=\frac{W_{t}^{D} / P_{t}^{D}}{A_{t} Z_{t}^{D}} .
$$

Intermediate goods producers solve a standard Calvo model profit-maximization problem with indexation. As shown in appendix 2 , inflation dynamics in each sector depend on one expected lead and one lag of inflation, and the sector-specific real marginal cost.

\subsection{Closing the Model}

\subsubsection{Market Clearing Conditions}

For intermediate goods, supply equals demand. We write the market clearing conditions in terms of aggregate quantities and, thus, multiply per capita quantities by population size of each country. In 
the non-durable sector, production is equal to domestic demand by savers $C_{H, t}$ and borrowers $C_{H, t}^{B}$ and exports (consisting of demand by savers $C_{H, t}^{*}$ and borrowers $C_{H, t}^{B^{*}}$ from the foreign country):

$n Y_{t}^{C}=n\left[\lambda C_{H, t}+(1-\lambda) C_{H, t}^{B}\right]+(1-n)\left[\lambda^{*} C_{H, t}^{*}+\left(1-\lambda^{*}\right) C_{H, t}^{B^{*}}\right]$.

Durable goods are only consumed by domestic households, and production in this sector is equal to residential investment for savers and borrowers:

$$
n Y_{t}^{D}=n\left[\lambda I_{t}+(1-\lambda) I_{t}^{B}\right]
$$

In the labor market, total hours worked has to be equal to the aggregate supply of labor in each sector:

$$
\int_{0}^{n} L_{t}^{k}(h) d h=\lambda \int_{0}^{n} L_{t}^{k, j} d j+(1-\lambda) \int_{0}^{n} L_{t}^{k, B, j} d j, \text { for } k=C, D .
$$

Credit market clearing implies that for domestic credit and international bond markets, the balance sheets of financial intermediaries are satisfied. Besides equation (3), this requires

$$
n \lambda B_{t}+(1-n) \lambda^{*} B_{t}^{*}=0 .
$$

Finally, aggregating the resource constraints of borrowers and savers, and the market clearing conditions for goods and financial intermediaries, we obtain the law of motion of bonds issued by the home country international financial intermediaries. This can also be viewed as the evolution of net foreign assets (NFA) of the home country:

$$
\begin{aligned}
n \lambda B_{t}= & n \lambda R_{t-1} B_{t-1}+\left\{(1-n) P_{H, t}\left[\lambda^{*} C_{H, t}^{*}+\left(1-\lambda^{*}\right) C_{H, t}^{B^{*}}\right]\right. \\
& \left.-n P_{F, t}\left[\lambda C_{F, t}+(1-\lambda) C_{F, t}^{B}\right]\right\}
\end{aligned}
$$

which is determined by the aggregate stock of last period's NFA times the interest rate, plus net exports. 


\subsubsection{Monetary Policy and Interest Rates}

Monetary policy is conducted at the currency union level by the central bank with an interest rate rule that targets union-wide CPI inflation and real output growth. The central bank sets the deposit rate in the home country, and the other rates are determined as described in the model. Let $\bar{\Pi}^{E M U}$ be the steady-state level of unionwide CPI inflation, $\bar{R}$ the steady-state level of the interest rate, and $\varepsilon_{t}^{m}$ an i.i.d. monetary policy shock. The interest rate rule is given by

$$
R_{t}=\left[\bar{R}\left(\frac{P_{t}^{E M U} / P_{t-1}^{E M U}}{\bar{\Pi}^{E M U}}\right)^{\gamma_{\pi}}\left(Y_{t}^{E M U} / Y_{t-1}^{E M U}\right)^{\gamma_{y}}\right]^{1-\gamma_{R}} R_{t-1}^{\gamma_{R}} \exp \left(\varepsilon_{t}^{m}\right)
$$

The euro-area CPI $\left(P_{t}^{E M U}\right)$ and real GDP $\left(Y_{t}^{E M U}\right)$ are given by geometric averages of the home and foreign country variables, using the country size as a weight:

$$
P_{t}^{E M U}=\left(P_{t}^{C}\right)^{n}\left(P_{t}^{C^{*}}\right)^{1-n}, \text { and } Y_{t}^{E M U}=\left(Y_{t}\right)^{n}\left(Y_{t}^{*}\right)^{1-n},
$$

where the national real GDPs are expressed in terms of non-durables:

$$
Y_{t}=Y_{t}^{C}+Y_{t}^{D} \frac{P_{t}^{D}}{P_{t}^{C}}, \text { and } Y_{t}^{*}=Y_{t}^{C^{*}}+Y_{t}^{D^{*}} \frac{P_{t}^{D^{*}}}{P_{t}^{C^{*}}} .
$$

\subsubsection{Macroprudential Policy}

Similar to Kannan, Rabanal, and Scott (2012), we introduce a macroprudential tool that aims at affecting the credit market conditions countercyclically. As shown in equations (3) and (4), the macroprudential instrument $\eta_{t}$ affects the equilibrium in the domestic credit market and affects the lending-deposit spread in each country. We interpret this macroprudential instrument as being deployed above and beyond current rules, which are static to a large degree. Hence, when we estimate the model, we set $\eta_{t}$ to a constant value of one. When we conduct an optimal macroprudential policy exercise in section 4.2 , we allow the instrument to be changed in order to maximize the weighted utility of all the citizens in the monetary union. A tightening of macroprudential policies will be reflected in a higher $\eta_{t}$, 
which will translate into a higher lending-deposit spread. Although we leave it unspecified, this could be implemented via additional capital surcharges, liquidity ratios, loan-loss provisions, or reserve requirements that reduce the amount of loanable funds by financial intermediaries. We assume that the instrument, in principle, can behave symmetrically and can go below one. In that case, the central bank or any other regulatory agency would provide liquidity to the banking sector to reduce the lending-deposit spread. This could be achieved via (conventional or unconventional) measures like a widening of collateral standards, the Funding for Lending Scheme launched by the Bank of England in 2012, or even a direct provision of liquidity to the real economy as in Gertler and Karadi (2011). In the welfare-maximizing exercise, we specify the macroprudential instrument as reacting to an indicator variable $\left(\Upsilon_{t}\right)$ :

$$
\eta_{t}=\left(\Upsilon_{t}\right)^{\gamma_{\eta}}, \quad \eta_{t}^{*}=\left(\Upsilon_{t}^{*}\right)^{\gamma_{\eta}^{*}}
$$

We study two main cases. In each country the macroprudential instrument reacts to (i) nominal credit growth or (ii) the creditto-GDP ratio. For both cases, the parameters $\gamma_{\eta}$ and $\gamma_{\eta}^{*}$ are either allowed to be different or are forced to be the same in the monetary union. In all cases, the indicator reacts to deviations from steady-state values.

This concludes the explanation of the model. In section 3, we conduct a Bayesian estimation of the model's parameters. In section 4, we examine optimal monetary and macroprudential policy rules by obtaining the optimal values of $\gamma_{\pi}, \gamma_{y}, \gamma_{R}, \gamma_{\eta}$, and $\gamma_{\eta^{*}}$ using the utility function of the four types of households in the monetary union (patient and impatient, in the home and foreign countries).

\section{Parameter Estimates}

We apply standard Bayesian methods to estimate the parameters of the model (see An and Schorfheide 2007). First, the equilibrium conditions of the model are normalized such that all real variables become stationary. This is achieved by dividing real variables in both countries by the level of non-stationary technology, $A_{t}$. Second, the dynamics of the model are obtained by taking a log-linear approximation of equilibrium conditions around the steady state 
with zero inflation and net foreign asset positions 14 Third, the solution of the model is expressed in state-space form and the likelihood function of the model is computed using a Kalman-filter recursion. Then, we combine the prior distribution over the model's parameters with the likelihood function and apply the Metropolis-Hastings algorithm to obtain the posterior distribution to the model's parameters 15

\subsection{Data}

We distinguish between a core (home country) and a periphery (foreign country) region of the euro area. Data for the core is obtained by aggregating data for France and Germany, whereas the periphery is represented by the GIIPS countries (Greece, Ireland, Italy, Portugal, and Spain). We use quarterly data ranging from 1995:Q4 through 2011:Q4 and eleven macroeconomic time series 16 For both regions we use five observables: real private consumption spending, real residential investment, the Harmonised Index of Consumer Prices (HICP), housing prices, and outstanding debt for households. We also include the three-month Euribor rate, which we use as a counterpart of the deposit rate in the core 17 The data is aggregated taking the economic size of the countries into account (measured by GDP). All data is seasonally adjusted, in case this was not done by the original source. We use quarterly growth rates of all price and quantity data and we divide the interest rates by 400 to obtain a quarterly and logged equivalent variable to the model. All data is finally demeaned.

\subsection{Calibrated Parameters}

Some parameters are calibrated because the set of observable variables that we use does not provide information to estimate them

\footnotetext{
${ }^{14}$ Appendix 2 details the full set of normalized, linearized equilibrium conditions of the model.

${ }^{15}$ The estimation is done using Dynare 4.3.2. The posterior distributions are based on 250,000 draws of the Metropolis-Hastings algorithm.

${ }^{16}$ Due to the short history of the EMU, we face a short time series. We include the years 1995-98 to increase the sample size. During those years most EMU countries were conducting monetary policy in a coordinated way.

${ }^{17}$ See appendix 1 for further details on the data set.
} 


\section{Table 1. Calibrated Parameters}

\begin{tabular}{|l|l|c|}
\hline$\beta$ & Discount Factor Savers & 0.99 \\
$\bar{\omega}$ & Loan-to-Value Ratio & 0.7 \\
$\bar{F}$ & Default Rate on Loans & 0.025 \\
$\bar{\sigma}_{\omega}$ & Steady-State Risk & 0.1742 \\
$\mu$ & Proportion of Housing Value Paid to & 0.2 \\
$\beta^{B}$ & $\quad$ Debt-Collection Agency & \\
$\eta$ & Discount Factor Borrowers & 0.985 \\
$\delta$ & Macroprudential Instrument & 1 \\
$\sigma$ & Depreciation Rate & 0.0125 \\
$n$ & Elasticity of Substitution between & 10 \\
$1-\tau$ & $\quad$ Intermediate Goods & 0.6 \\
$1-\tau^{*}$ & Size of Core Economies & 0.06 \\
$\alpha$ & Fraction of Imported Goods from Periphery & 0.09 \\
& to Core Economies & 0.94 \\
\hline
\end{tabular}

(table 1). We assume that the discount factors are the same in both countries $\left(\beta=\beta^{*}\right.$ and $\left.\beta^{B}=\beta^{B^{*}}\right)$. We set the discount factor of savers to $\beta=0.99$. The steady-state LTV ratio, which also determines the cut-off point for defaulting on a loan, is set to $\bar{\omega}=0.7$ and equally across countries, according to euro-area data such as Gerali et al. (2010). We set the default rate on loans, $\bar{F}($.$) , to 2.5$ percent 18 As a result, the steady-state value of the risk shock is $\bar{\sigma}_{\omega}=0.1742$. We set the housing agent fee to $\mu=0.2$, which is a value higher than that calibrated by Forlati and Lambertini (2011) but lower than the recovery rates for loans estimated for the United States 19 Using these values, the zero-profit condition for financial intermediaries, and the consumption Euler equation for borrowers, we obtain a discount factor of borrowers of $\beta^{B}=0.985$. As discussed in the

\footnotetext{
${ }^{18}$ It is difficult to find non-performing loans for household mortgages only. Therefore, we use non-performing loans as a percentage of total loans for the euro area between 2000 and 2011 taken from the World Bank World Development Indicators database (http://data.worldbank.org/topic/financial-sector).

${ }^{19}$ See Mortgage Bankers Association (2008).
} 
previous section, we set the macroprudential instrument to $\eta=1$ to estimate the model.

The depreciation rate is assumed to be 5 percent (annual) and equal across countries $\left(\delta=\delta^{*}=0.0125\right)$. The degree of monopolistic competition in the goods markets $\sigma$ is the same across sectors and countries, implying markups of 10 percent. We set the size of the core countries in the euro area to $n=0.6$, based on GDP data. The bilateral trade parameter $1-\tau$ is calibrated based on the weighted average of total imports to private consumption from periphery to core economies. The analogous parameter for the periphery $1-\tau^{*}$ is calculated in a similar way but is rounded to ensure that the trade balance and the net foreign asset position are zero in the steady state. Finally, we assume that the size of the durable and non-durable sectors is the same for the core and the periphery of the euro area $\left(\alpha=\alpha^{*}\right)$. The assumptions of symmetry and balanced trade make it easier to compute a steady state where all relative prices in all sectors are equal to one and where all per capita quantities are the same.

\subsection{Prior and Posterior Distributions}

In table 2 we present the prior distributions, the posterior mean, and the 90 percent credible set of selected estimated parameters 20 To save space, we present the estimated parameters of the shock processes in appendix 3. Because we face the problem of a short sample, in addition to calibrating some parameters, we restrict others to be the same across countries. More specifically, we only allow the parameters related to nominal rigidities to differ across sectors and countries, in order to permit quantitatively different transmission channels of monetary policy. On the other hand, the parameters relating to preferences, adjustment costs, and the fraction of savers

\footnotetext{
${ }^{20}$ For each step of the Metropolis-Hastings algorithm, given a draw of the parameters that we wish to estimate, we must solve for the steady-state levels of consumption of durables and non-durables, for hours worked in each sector by each type of agent, and for each country. Then, these steady-state values are needed to obtain the log-linear dynamics to the system. Also, for every draw, we solve for the weight of non-durables in the utility function in each country $(\gamma$ and $\left.\gamma^{*}\right)$, which is not a free parameter but rather a function of $\alpha, \delta, \lambda, \beta, \beta^{B}, \varepsilon, \varepsilon^{B}$, and $\varphi$.
} 


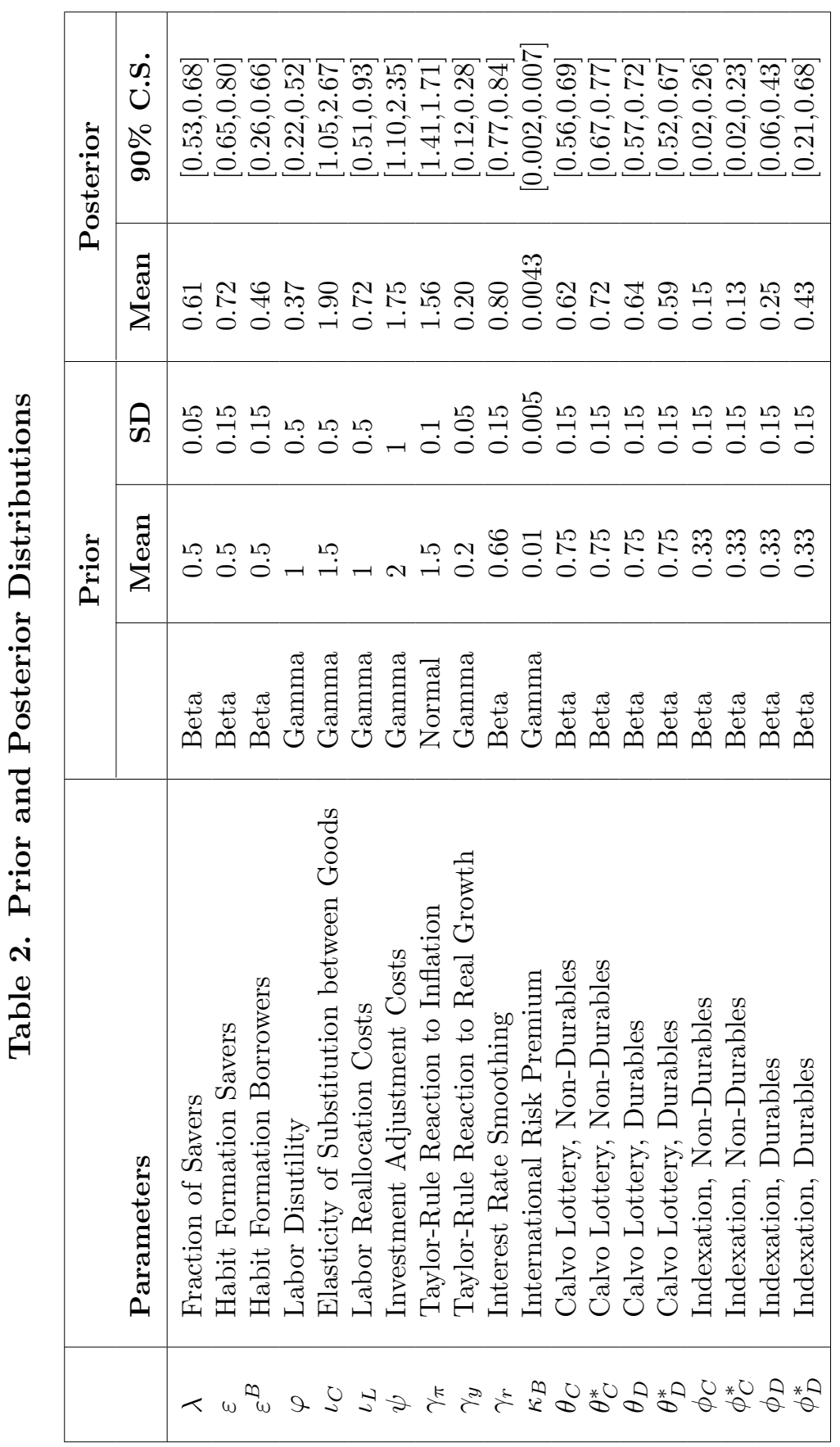


are assumed to be the same in both countries. We assume that the AR(1) coefficients of the shocks are the same across countries, but we allow the standard deviation of the shocks to differ across countries. Also, in order to better capture the correlation of key macrovariables across countries, we assume that the housing demand shock and the total factor productivity (TFP) shock in non-durables has a common component across countries. For instance, the housing demand shock follows:

$$
\begin{aligned}
\log \left(\xi_{t}^{D}\right) & =\rho_{\xi, D} \log \left(\xi_{t-1}^{D}\right)+\varepsilon_{t}^{\xi, D}+\varepsilon_{t}^{\xi, D, C O M} \\
\log \left(\xi_{t}^{D^{*}}\right) & =\rho_{\xi, D} \log \left(\xi_{t-1}^{D^{*}}\right)+\varepsilon_{t}^{\xi, D^{*}}+\varepsilon_{t}^{\xi, D, C O M},
\end{aligned}
$$

where the country-specific $\left(\varepsilon_{t}^{\xi, D}\right.$ and $\left.\varepsilon_{t}^{\xi, D^{*}}\right)$ as well as common $\left(\varepsilon_{t}^{\xi, D, C O M}\right)$ innovations are normal i.i.d. with mean zero.

First, we comment on the parameters that relate to preferences of borrowers and savers. We opt for a prior distribution centered at 0.5 for the fraction of savers in the economy. We set a highly informative prior by setting a small standard deviation of 0.05 . The posterior mean suggests a somewhat larger fraction (0.61) to fit the macro data 21 Interestingly, we find that the habit formation coefficient for borrowers is smaller than the one for savers, even though we set the same prior for both coefficients. These estimates suggest that above and beyond the effect of the financial accelerator, consumption of savers is less volatile than consumption of borrowers, who will react more to changes in their relevant (lending) interest rates. We center the priors related to the elasticity of substitution between home and foreign non-durables, the elasticity of labor supply, and the coefficient measuring costly labor reallocation to parameters available in the literature (Smets and Wouters 2003, Adolfson et al. 2007, and Iacoviello and Neri 2010). We find a large elasticity of substitution between home and foreign goods (the posterior mean of 1.9 is higher than the prior mean of 1.5). Regarding the coefficients that determine labor supply, we find that the posterior mean of the labor disutility coefficient $\varphi$ and the degree of costly labor reallocation is about one-third, which is similar to Iacoviello and Neri (2010).

\footnotetext{
${ }^{21}$ Gerali et al. (2010) calibrate this fraction to be 0.8 for the euro area.
} 
The coefficients on the Taylor rule suggest a strong response to inflation fluctuations in the euro area (coefficient of 1.56, close to the prior mean), a moderate response to real GDP growth (posterior mean of 0.2 ), and a high degree of interest rate inertia (0.80). We opt for a gamma prior for the risk premia elasticity $\kappa_{B}$ between countries with a mean of 0.01 . We find that the risk premium elasticity between countries moves about 0.43 basis points with a 1 percent increase in the external debt-to-GDP ratio.

Next, we comment on the coefficients regarding nominal rigidities. We opt for beta prior distributions for Calvo probabilities with a mean of 0.75 (average duration of price contracts of four quarters) and standard deviation of 0.15 . We set the mean of the prior distributions for all indexation parameters to 0.33 . This set of priors is consistent with the survey evidence on price setting presented in Fabiani et al. (2006). The posterior means for the Calvo lotteries are lower than the prior means, and in all cases prices are reset roughly every three quarters. Overall, these probabilities are lower than other studies of the euro area like Smets and Wouters (2003). We also find that price indexation is low in all prices and sectors. One possible explanation is that we are using a shorter and more recent data set where inflation rates are less sticky than in the 1970s and 1980s.

Table 8 in appendix 3 presents the prior and posterior distributions for the shock processes. We comment on two results. First, the common innovations to non-durable technology shocks and durable preference shocks are important, and as we discuss in the next subsection, they are key to matching cross-country correlations of some key macro-variables. Second, the mean of the (log) risk shock is $\log (0.1742)=-1.74$. We set a prior standard deviation for the innovation to the housing risk shock of 0.25 (that is, 25 percent), such that, roughly, the two-standard-deviation prior interval is between -1.25 and -2.25 . Given the properties of the log-normal distribution, this means that the default rate for mortgages ranges between 0.04 and 13.6 percent with 95 percent probability. This seems to be an acceptable range for euro-area member states 22 The estimates for the quality shock in the periphery are similar to the prior, while in

\footnotetext{
${ }^{22}$ See the World Development Indicators database from the World Bank.
} 
the core there seems to be much less risk volatility, as reflected by the posterior.

\subsection{Model Fit and Variance Decomposition}

We present the standard deviation and first five autocorrelations of the observable variables, and their counterpart in the model implied by the posterior distribution of the parameters, to understand how well the model fits the data. In table 3 , the first row for each entry is the data; the second row is the 90 percent confidence set implied by the model estimates. The model does reasonably well in explaining the standard deviation of all variables in the periphery. However, the model overpredicts the volatility of prices and quantities in both sectors in the core of the euro area, despite having allowed for different degrees of nominal rigidities, indexation, and different standard deviations of shocks. Finally, the model correctly implies that credit growth in the periphery is more volatile than in the core. The model also does a better job of explaining the persistence of variables in the periphery than in the core, and does a good job of predicting the persistence of interest rates. It slightly overpredicts the persistence of CPI inflation in the periphery, and slightly underpredicts the persistence of residential investment, consumption growth, and house prices. In the core, the model has a harder time fitting the lack of persistence in CPI inflation, residential investment, and consumption growth.

The model captures most of the co-movement between main aggregates within and across countries of the euro area, which is especially important for the design of optimal monetary and macroprudential policies. In table 4 we present the contemporaneous correlation of selected observable variables in the data and in the model (90 percent confidence set) 23 Among the successes, we note that the model explains the correlation between house prices and residential investment within each area well. The model also fits well the correlation of house-price inflation, consumption growth, and residential investment growth across countries. The model can explain the co-movement between consumption and residential investment

\footnotetext{
${ }^{23}$ Table 9 in appendix 3 presents contemporaneous correlation of all observable variables.
} 


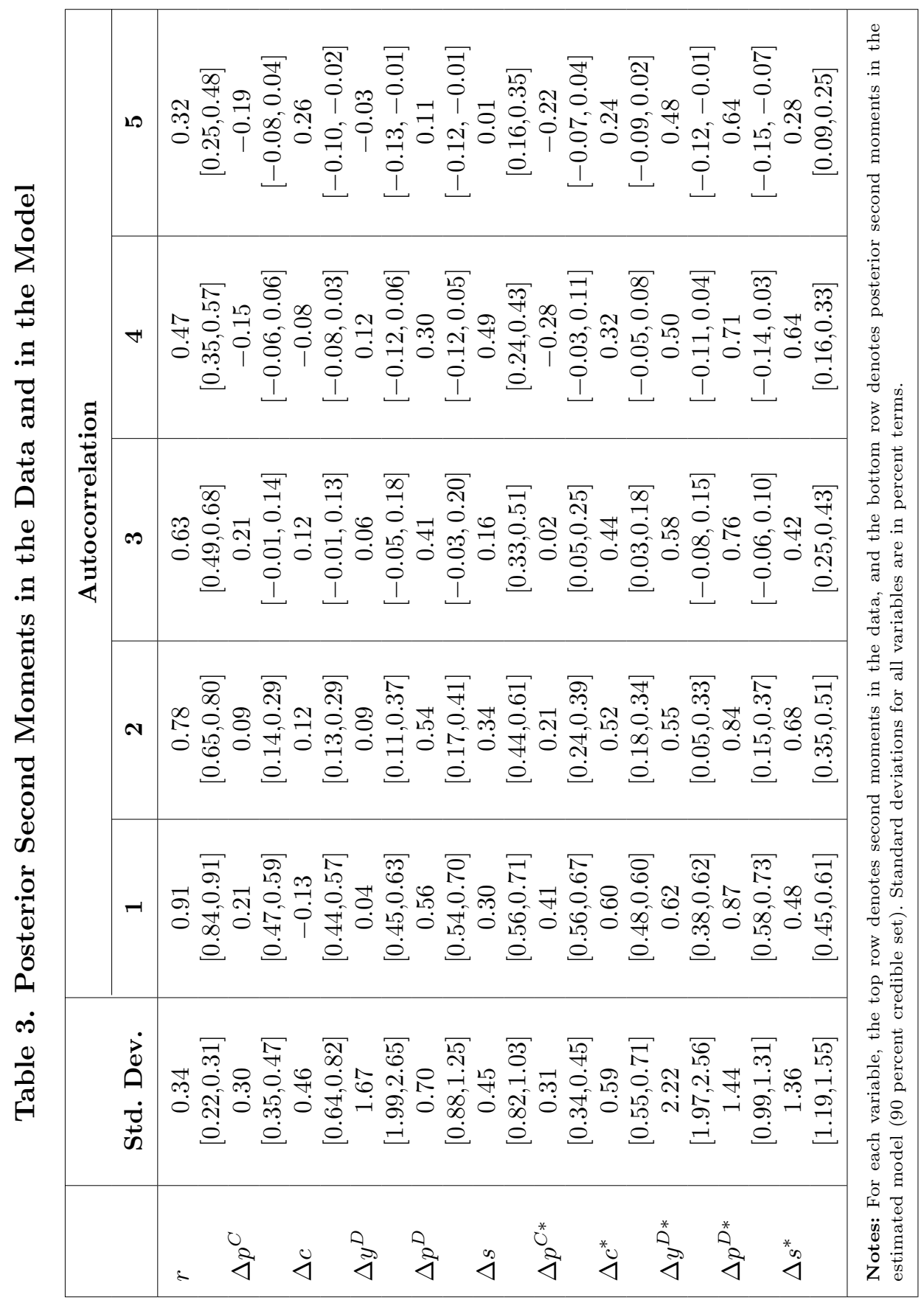




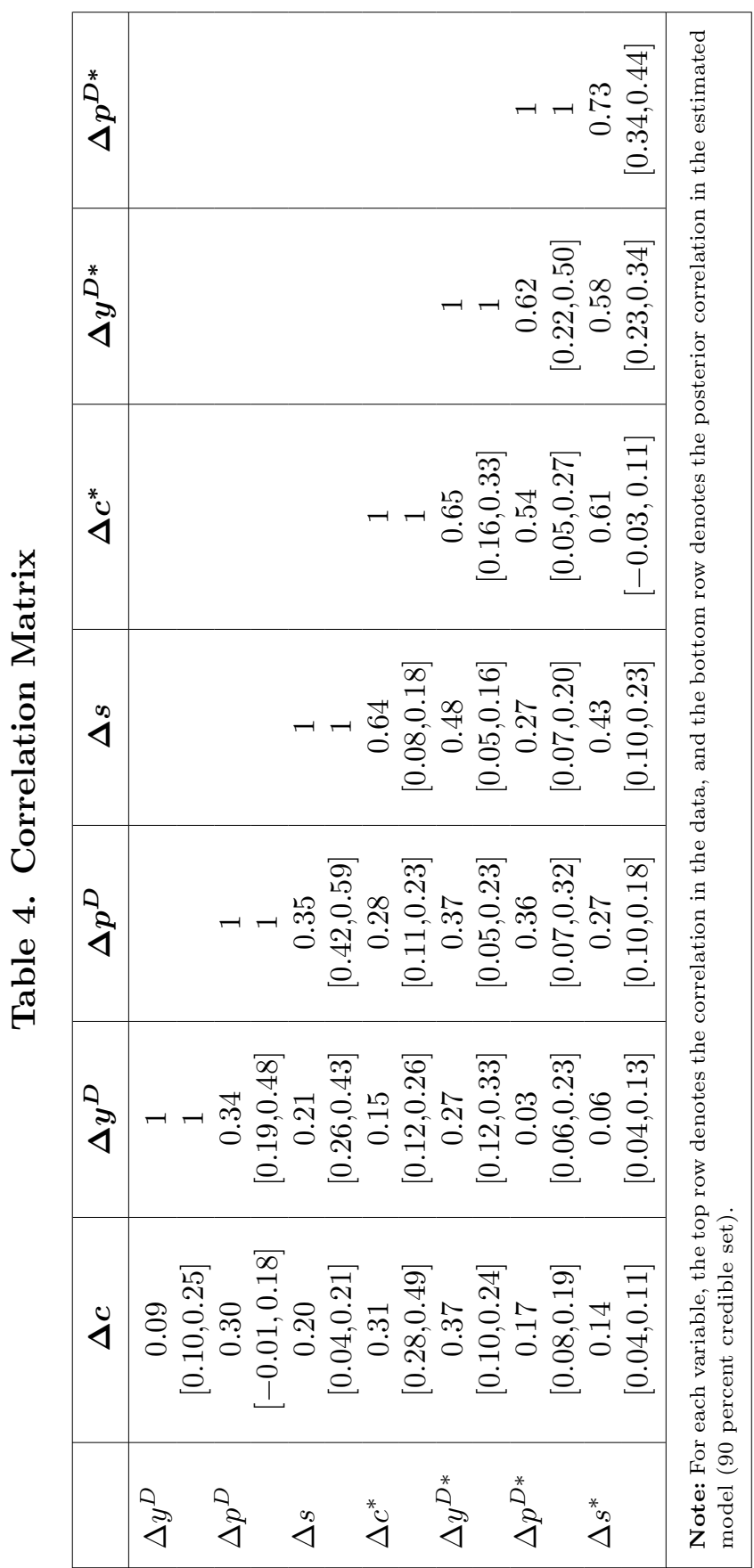


in the core, but fails at explaining the co-movement in the periphery. Finally, the model does a good job of explaining the correlation of credit with main macroeconomic variables in the core. The model does a worse job of explaining the correlation of credit with other macro-aggregates in the periphery, because it implies a correlation that is smaller than in the data, while still getting the sign right.

We briefly discuss the results from the variance decomposition exercise. To save space, we present the table with the 90 percent confidence set for the share of the variance of each variable explained by the two most important shocks in appendix 3 (table 10). For all variables, two shocks are enough to explain at least half of their variance, while the remaining shocks explain a small fraction of the variance one at a time. In most cases, each variable in each country and sector is mostly explained by technology and preference shocks in that country and sector. For instance, residential investment and housing prices are mostly explained by a combination of supply and demand shocks. There are no important spillovers from shocks originating in one country or sector to another. There are two exceptions to this pattern. CPI inflation in both areas is explained by the common innovation component to non-durable technology, and monetary shocks. The unit-root shock to aggregate technology explains an important fraction of volatility of consumption growth in both areas. Finally, it is worth noting that in each country, the volatility of credit is mostly explained by risk shocks and by housing demand (durable preference) shocks. But risk shocks do not have an important impact on the volatility of real macroeconomic variables.

\subsection{Model Comparison: A Brief Discussion}

The model we have presented up to now is the one that appears to explain the observable data best. In this sub-section, we briefly discuss other model specifications that we have estimated. The full results including model comparison statistics such as the marginal likelihood for each model, and posterior distributions for the model's parameters and second moments implied by each model are available upon request.

First, we discuss the main findings of estimating a model with only savers by setting $\lambda=1$. In this case, the model abstracts from 
financial frictions and, thus, we also dropped the risk shocks in the housing market. Furthermore, credit growth did not enter the set of observable variables anymore, which complicated using the marginal likelihood as a model comparison statistic. Omitting financial frictions, we found that most parameter estimates turn out to be very similar to what we reported in table 2 , and the posterior second moments are also very similar to the model with borrowers and savers. Hence, we find that in order to fit macroeconomic variables such as CPI inflation, house prices, consumption, and residential investment, it is not necessary to introduce financial frictions in the model. However, the model we present in this paper allows us to analyze the interaction between credit aggregates and other macroeconomic variables.

Second, we also estimated our model without common innovations in non-durable technology shocks and durable preference shocks across countries. In this case, the model fit to the data was worse when trying to explain the correlation of consumption growth, residential investment growth, and house prices across countries. We also experimented with introducing common innovations to other shocks in the model but found that the estimates of the standard deviations were quite small, and hence did not change the implications of the model for posterior second moments.

Third, instead of assuming that the $\mathrm{AR}(1)$ coefficients of the shocks are the same across countries, we allowed them to be different. But this did not improve the model fit. In addition, following the results in Christiano, Motto, and Rostagno (2013), we also introduced news shocks in the housing quality shocks as follows:

$$
\log \left(\sigma_{\omega, t}\right)=\left(1-\rho_{\sigma_{\omega}}\right) \log \left(\bar{\sigma}_{\omega}\right)+\rho_{\sigma_{\omega}} \log \left(\sigma_{\omega, t-1}\right)+\sum_{p=0}^{s} u_{\omega, t-p}
$$

for $s=1$ to 4 . We found that the marginal likelihood favored the model without news shocks and, therefore, we excluded them from the analysis. When we performed a posterior variance decomposition exercise, we found that lagged innovations to risk explained a fraction of the variance of credit, but they explained a very small fraction (less than 1 percent) of the variance of observed real macroeconomic variables. 
Finally, we estimated the model with a targeting rule of the type

$$
\frac{P_{t}^{E M U} / P_{t-1}^{E M U}}{\bar{\Pi}^{E M U}}+\lambda_{p}\left(Y_{t}^{E M U} / Y_{t-1}^{E M U}\right)=0
$$

instead of a Taylor-type rule as in equation (24). We also estimated a version of the model where funding costs for financial intermediaries are the same across countries 24 Neither of these two extensions improved model fit, so they were discarded.

\section{Policy Experiments}

This section discusses the optimal monetary and macroprudential policy mix for the euro area. For this purpose, we analyze the performance of different policy rules using the estimated parameter values and shock processes of the previous section. We evaluate aggregate welfare by taking a second-order approximation to the utility function of each household and country, and to the equilibrium conditions of the model, at the posterior mean of the model's parameters. We assume that policymakers maximize the welfare function of all citizens of the euro area (borrowers and savers in the core and periphery) using their population weights. That is, we define the welfare function as

$$
\begin{aligned}
\mathcal{W}^{E M U} & =n \mathcal{W}+(1-n) \mathcal{W}^{*} \\
\text { with } \mathcal{W} & =\lambda \mathcal{W}^{S}+(1-\lambda) \mathcal{W}^{B} \text { and } \mathcal{W}^{*}=\lambda^{*} \mathcal{W}^{S^{*}}+\left(1-\lambda^{*}\right) \mathcal{W}^{B^{*}}
\end{aligned}
$$

where $\mathcal{W}^{S}$ is the welfare of core savers, which is evaluated by taking a second-order approximation to the utility function (6) and subtracting the value of the utility function at the non-stochastic steady state $25 \mathcal{W}^{B}$ is the welfare of core borrowers, which is evaluated similarly using their utility function $(11) . \mathcal{W}^{S^{*}}$ and $\mathcal{W}^{B^{*}}$ are defined analogously for the periphery households.

\footnotetext{
${ }^{24}$ In this case, in order to achieve stationarity in the model, we assumed that there are complete markets for securities traded internationally.

${ }^{25}$ That is, $\mathcal{W}^{S}=E\left[U\left(C_{t}, D_{t}, L_{t}\right)\right]-U(\bar{C}, \bar{D}, \bar{L})$, where $E[\cdot]$ is the expectation operator, $U$ is a second-order approximation to the utility function, and $\bar{C}, \bar{D}$, and $\bar{L}$ are the non-stochastic steady-state values.
} 
Basel III calls for regulators to intervene in case of excessive credit growth. We aim at studying the pros and cons of reacting to credit indicators, either by using monetary or macroprudential policies. First, we study optimal monetary policy rules by optimizing over the coefficients of the estimated Taylor rule. Second, we extend the Taylor rule to react to different measures involving credit (nominal credit growth and the credit-to-GDP ratio), and optimize over the additional coefficient. Third, we include a macroprudential rule that "leans against the wind" of credit cycles. As we discussed in section 2.4.3, we assume that macroprudential policies affect the credit market clearing condition (3) by using the $\eta_{t}$ instrument directly. To increase lending spreads, different measures could be used, such as additional capital surcharges, liquidity ratios, loan-loss provisions, or reserve requirements. We assume that the steady-state value of $\eta=1$, and that the instrument may also take values smaller than one. In this latter case, commercial banks could lend beyond their loanable funds (i.e., the deposit base and foreign bonds) by obtaining liquidity from the central bank. As in the case of extended optimal monetary policy, the macroprudential instrument reacts whenever these different measures involving credit deviate from their steady-state values. To obtain the optimal policy response of the central bank using the nominal interest rate, we exclude the monetary policy shock $\varepsilon_{t}^{m}$ in all of these simulations 26

\subsection{Optimal Monetary Policy}

\subsubsection{Estimated Taylor Rule}

We start by optimizing over the coefficients of the estimated Taylor rule (27). In particular, we optimize over the coefficients of the reaction to area-wide CPI inflation, area-wide real GDP growth, and interest rate smoothing. We truncate the coefficients of the response to inflation and output growth in the Taylor rule. As in SchmittGrohé and Uribe (2007), we find that the welfare improvements are numerically negligible when the coefficients of the Taylor rule have

\footnotetext{
${ }^{26}$ Including the monetary policy shock in our policy experiments primarily affects the results for the inertia coefficient. With i.i.d. monetary shocks as in the estimated model, the optimal degree of inertia moves towards zero in most simulations.
} 
reached a certain value but are left unbounded. In order to speed up the maximization routines, it is thus helpful to restrict the coefficients $\gamma_{\pi}$ and $\gamma_{y}$ to the interval $[0,5]$, while the coefficient on interest rate smoothing is restricted to the interval $[0,1]$.

In the first row of table 5 , we show the optimized coefficients of the estimated Taylor rule. We also compute the improvement in welfare with respect to the estimated Taylor rule in percentage terms. The optimal monetary policy suggests stronger responses to euro-area CPI inflation and output growth than the estimated coefficients, and less interest rate smoothing. In this case, the welfare of all households in the euro area improves by 0.03 percent of steadystate consumption, but more so for savers in both countries. In fact, welfare for borrowers in the periphery declines slightly.

\subsubsection{Extending the Taylor Rule with Financial Variables}

Next, we examine the welfare improvement when the ECB is allowed to react to credit indicators (nominal credit growth and the creditto-GDP ratio in the euro area). We either optimize (i) over all the coefficients of the Taylor rule, including the coefficient of the financial variable, or (ii) only over the coefficient of the additional indicator, leaving the others at their estimated values. In all cases the coefficients are again truncated to a maximum value of five. There is some welfare improvement in reacting to nominal credit growth, but no welfare improvement in reacting to the credit-to-GDP ratio. The optimal response to nominal credit growth is $\gamma_{s}=1.31$. The same qualitative results hold when we keep the coefficients of the Taylor rule at their estimated values and only optimize over the additional parameter.

Having monetary policy react to euro-area nominal credit growth improves on EMU welfare. Welfare of savers increases between 0.03 and 0.11 percent of lifetime consumption, compared with the estimated Taylor rule. Yet, welfare of borrowers declines in both areas. This captures an interesting aspect of our results. The heterogeneity in the model allows us to identify the winners and losers of different policy regimes in the EMU. We will further examine this result below in the context of impulse response functions, after discussing macroprudential regulation. 


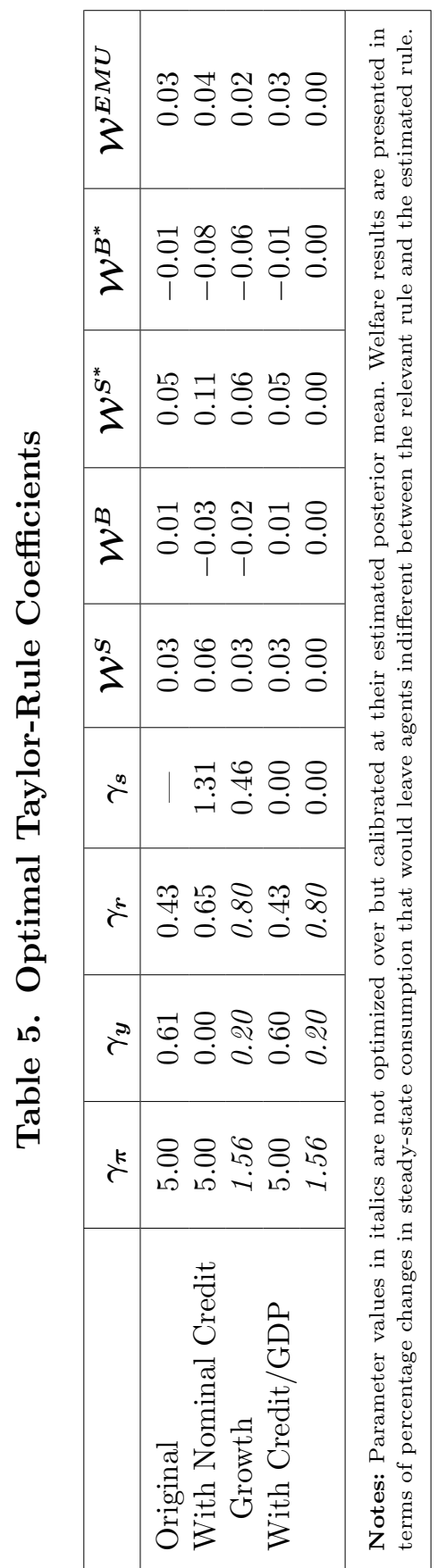




\subsection{Macroprudential Regulation}

In this sub-section, we focus on macroprudential policies that are set countercyclically to maximize EMU welfare but are implemented at the national level. Hence, we analyze the optimal policy regime consisting of the estimated Taylor rule together with national macroprudential rules (25) and optimize over the parameters of these three rules in order to maximize the welfare criterion (27). In this scenario, monetary policy reacts to union-wide developments, while macroprudential policy responds to domestic developments in each country. The coefficients of these policy rules are jointly decided to maximize welfare at the aggregate (EMU) level. Since we allow the macroprudential rule to affect credit variables directly, we no longer include the reaction to credit in the Taylor rule. Therefore, the macroprudential instrument can be viewed as an alternative to having monetary policy react to indicators beyond CPI inflation and output growth. In this sense, we study the Svensson (2012) suggestion that monetary policy should be in charge of price stability while macroprudential policy should address financial stability.

In table 6 we consider the following combinations of cases: (i) macroprudential regulation reacts to either nominal credit growth or the credit-to-GDP ratio, (ii) the coefficients of the Taylor rule are the estimated ones, or are optimized with the parameters of the macroprudential rule, and (iii) the coefficients of the macroprudential policies are allowed to change across countries, or are restricted to be the same.

Several interesting results arise from this exercise. First of all, in some cases there are winners and losers of introducing macroprudential policies. The only policy that improves welfare for each type of agent, yet does not maximize EMU-wide welfare, is to have macroprudential policy react to nominal credit growth. In this regime, all households experience increases in welfare between 0.01 and 0.19 percent of lifetime consumption. Furthermore, there are no big numerical differences in welfare if we impose the restriction that the coefficients are the same across countries. Second, the macroprudential policy that delivers the highest welfare (reacting to the credit-to-GDP ratio) is highly divisive, since savers benefit greatly from it, especially in the periphery where they experience a welfare gain of 0.62 percent of lifetime consumption, while borrowers witness 


\begin{tabular}{|c|c|c|c|c|}
\hline 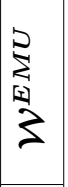 & & 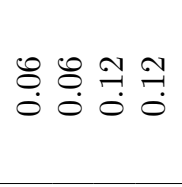 & & 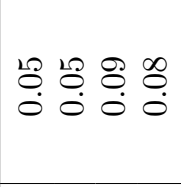 \\
\hline$\stackrel{*}{n}$ & & 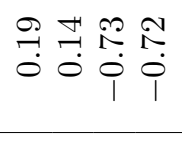 & & 듬두웅 \\
\hline${ }_{2}^{*}$ & & 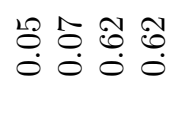 & & 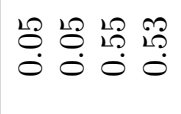 \\
\hline$\sum^{n}$ & & 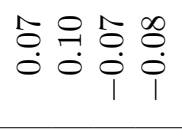 & & $\begin{array}{llll}\dot{D} & 0 & 0 & 0 \\
0 & 0 \\
0 & 0 & 0 & 0 \\
\end{array}$ \\
\hline $3_{3}^{2}$ & 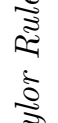 & 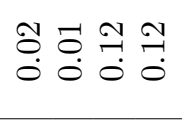 & 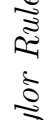 & 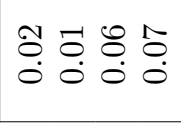 \\
\hline${ }^{*} \approx$ & $\begin{array}{l}-1 \\
\mathbb{J} \\
\text { జ్ }\end{array}$ & 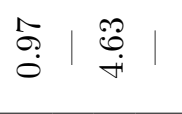 & 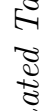 & 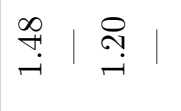 \\
\hline ह & $\begin{array}{l}\sqrt{\pi} \\
0 \\
0\end{array}$ & 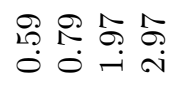 & 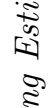 & 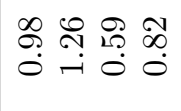 \\
\hline 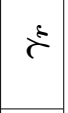 & $D$ & 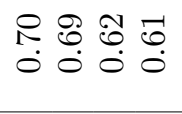 & $D$ & $\mid \begin{array}{llll}2 & 0 & 0 & 0 \\
\infty & \infty & \infty & \infty \\
0 & 0 & 0 & 0\end{array}$ \\
\hline$i^{2}$ & & 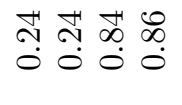 & & 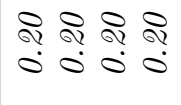 \\
\hline$c^{k}$ & & 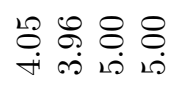 & & 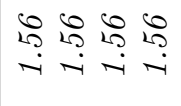 \\
\hline & & 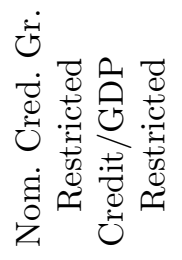 & & 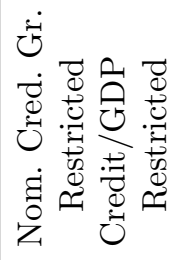 \\
\hline
\end{tabular}


an important decrease of welfare with respect to the estimated rule (a decline of 0.73 percent of lifetime consumption in the periphery). These results hold when we use the estimated Taylor rule and when we optimize over the coefficients of the Taylor rule.

Why is it the case that the welfare of borrowers declines under some optimal regimes of monetary and macroprudential policy? We discuss several impulse responses to understand under which conditions macroprudential policy improves welfare. In figures 1 and 2 we plot the impulse responses to a housing demand shock and a risk shock in the periphery. We choose these shocks because the periphery of the euro area experienced a larger boom-bust cycle in housing prices and credit than the core, especially in Spain and Ireland. After a housing demand shock (normalized such that nominal house prices increase by 1 percent in the periphery), GDP, CPI inflation, house prices, and credit-to-GDP increase in the periphery under the estimated rule (figure 1). In the core, GDP increases slightly, while all other variables fall because the ECB tightens rates due to above-normal CPI inflation and growth in the periphery. But the spillover effects tend to be quantitatively small. In the periphery, both borrowers and savers increase residential investment demand, and consumption behaves very differently. Savers reduce their consumption expenditures because they want to tilt spending towards housing, but borrowers increase non-durable consumption because higher house prices and residential investment improve their ability to borrow. This is the accelerator mechanism at work.

The optimal monetary policy response leads to a decline in the response of all real quantities in the core and a smaller response of CPI inflation in the periphery, but to a recession in the core. In this sense, the core is forced to pay for excesses committed by the periphery. But even in this case, the stronger monetary policy stance on CPI inflation and growth does not contain accelerator effects to really affect the credit-to-GDP ratio in the periphery. In order to achieve this, the use of macroprudential measures is necessary: For this reason, we now add the macroprudential rule that reacts to the credit-to-GDP ratio optimally (table 6). As a result, credit-to-GDP in the periphery increases to a lesser extent, there are fewer accelerator effects, and hence the stance of monetary policy can be softened in the EMU as a whole (compared with the optimal monetary policy case). Overall, the regime of optimal monetary plus 

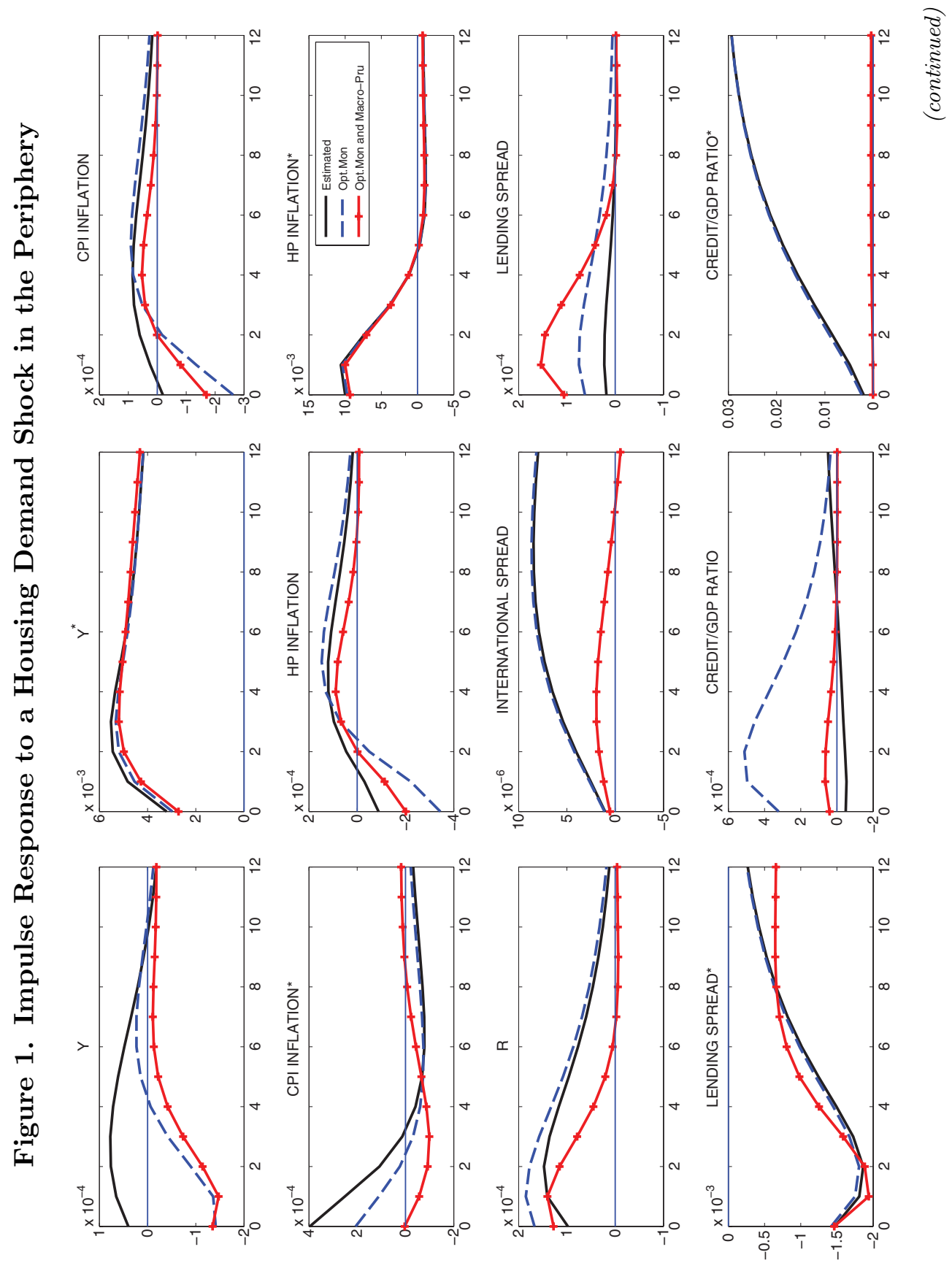

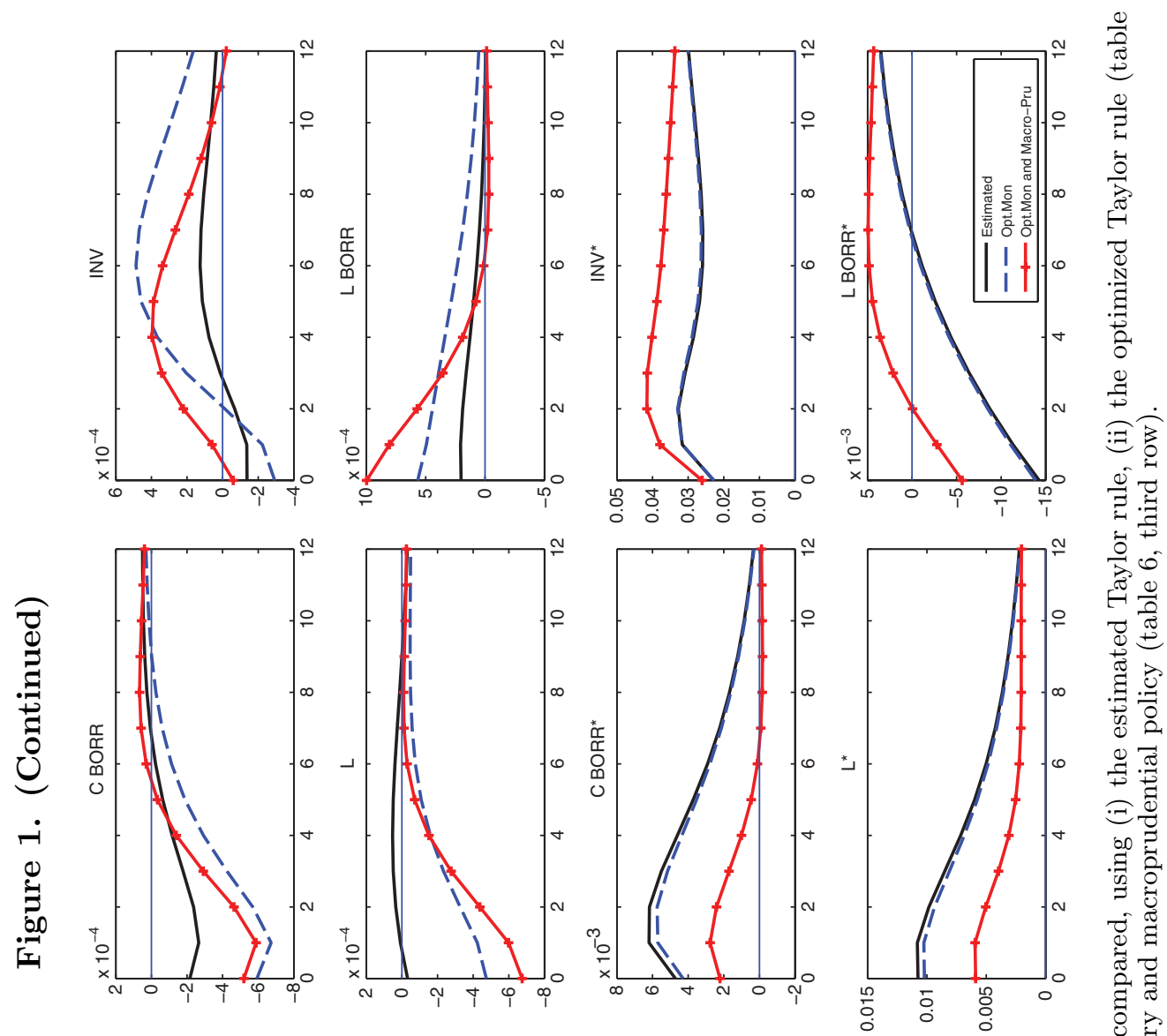

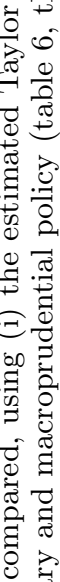
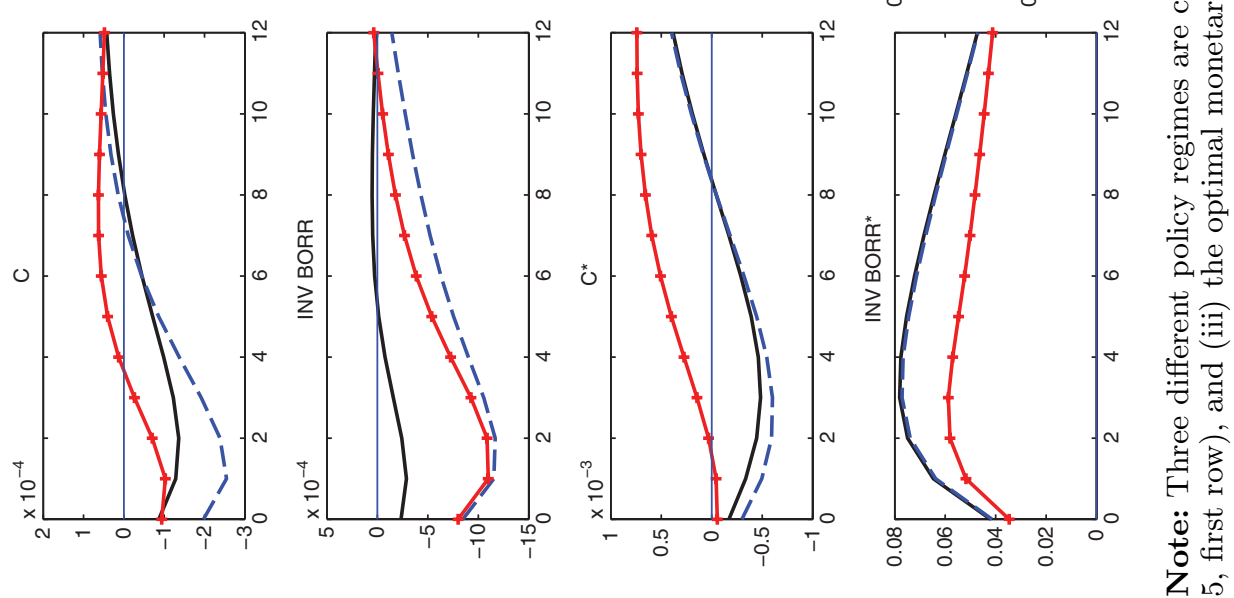

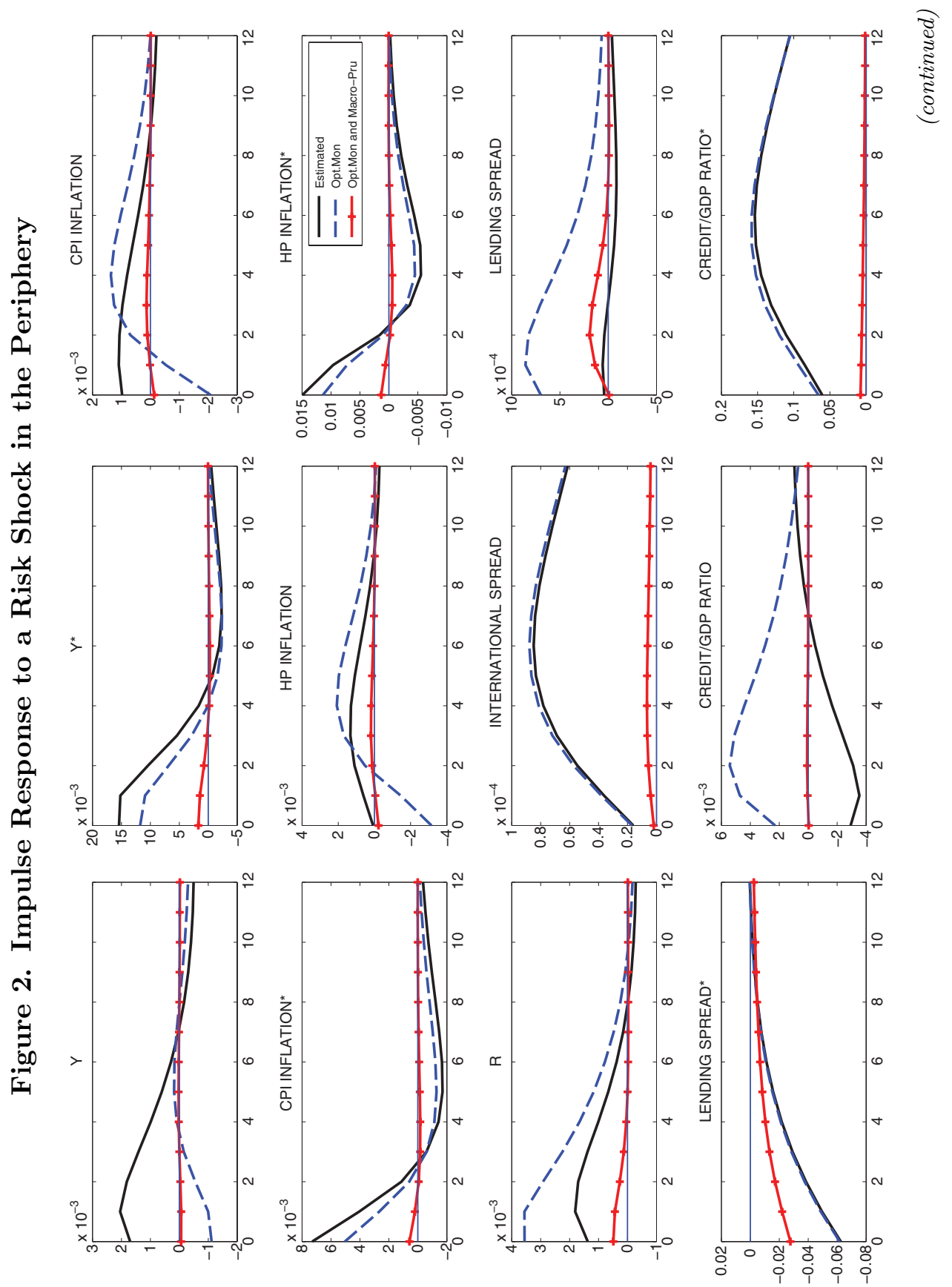

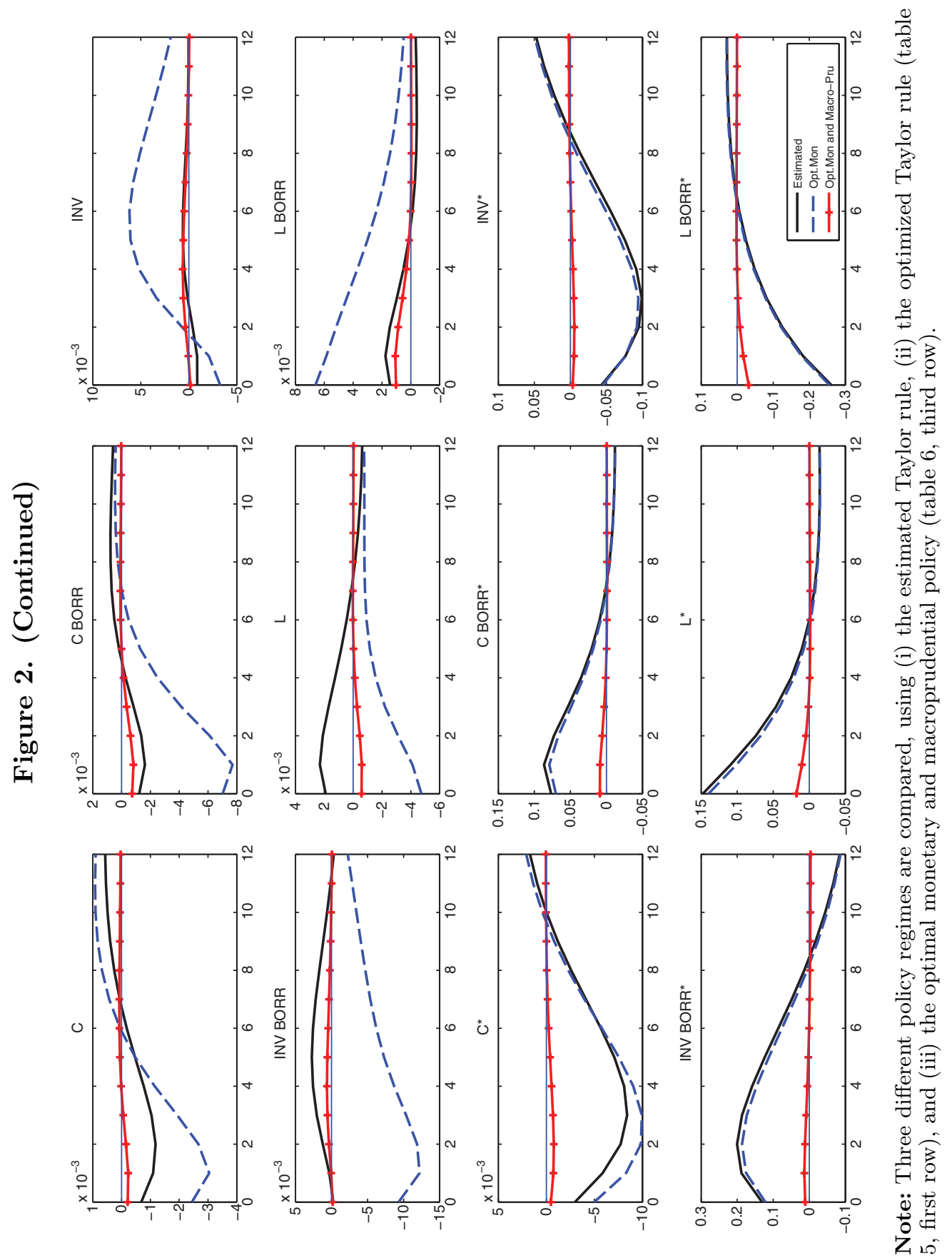
macroprudential policy delivers more stability on all real quantities in the periphery, and this improves welfare. However, this last regime cannot fully offset the negative spillover effects from the periphery to the core borrowers. Similar qualitative results would hold if the housing boom was in the core, but with core savers and borrowers benefiting more from stability using macroprudential policies.

A negative risk shock in the periphery has very similar effects on most variables in the periphery as the housing demand shock. When risk declines, the lending-deposit spread falls in the periphery (the shock is normalized such that spreads decline by 25 basis points on an annualized basis), triggering an increase in the creditto-GDP ratio. Under the estimated rule, consumption and residential investment by borrowers increase in the periphery, but they decline for savers. In the aggregate, GDP increases in the periphery, and increased demand by borrowers also increases GDP in the core, mostly through the net exports channel. However, higher inflation leads to an increase of interest rates that makes spending fall for both borrowers and savers in the core. The optimal monetary policy tries to stabilize CPI inflation by increasing interest rates, which leads to reductions of spending for all other households in the EMU, and a recession and deflation in the core. As in the case of the housing demand shock, optimal monetary policy cannot do much to offset the accelerator effects, while the use of macroprudential tools delivers overall stability and takes the pressure off the EMU-wide interest rate. If the risk shock had affected the core, it would have had a similar impact on core variables as the one described here for periphery variables, and vice versa.

When does the use of macroprudential tools lead to inferior welfare outcomes, especially for borrowers? In figure 3 we plot the effect of an innovation to the EMU-wide (one-standard-deviation) permanent technology shock. In this case, macroprudential policies increase the countercyclicality of the lending-deposit premium, increasing the volatility of borrower-specific variables and reducing their welfare. When a permanent technology hits the economy, this increases the level of real variables permanently (however, growth rates and transformed variables remain stationary). Since this is a permanent shock and both economies are quite symmetric, the effects are similar in both areas of the EMU. Under the estimated policy rule, consumption and residential investment by all agents moves smoothly to the 

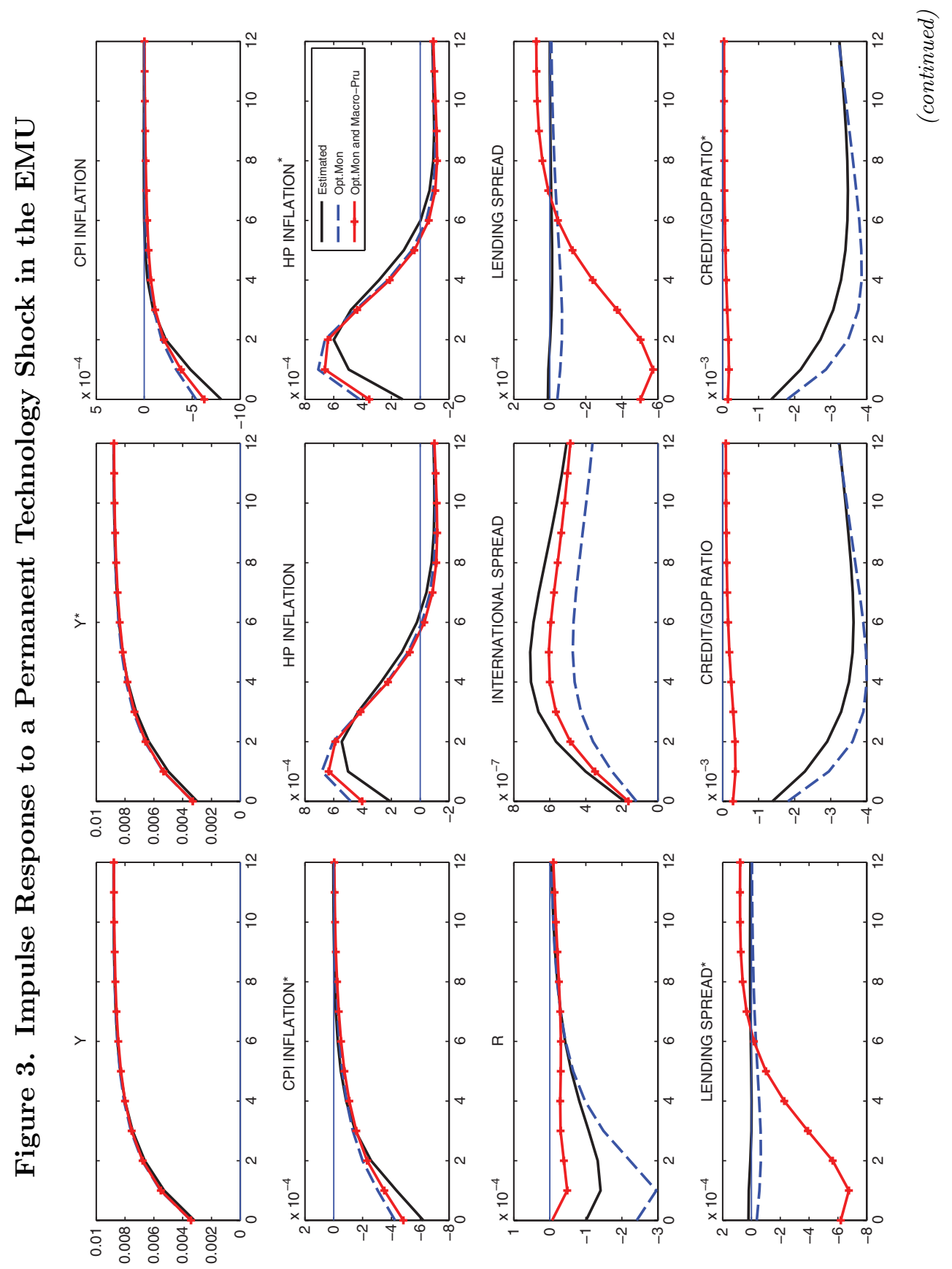

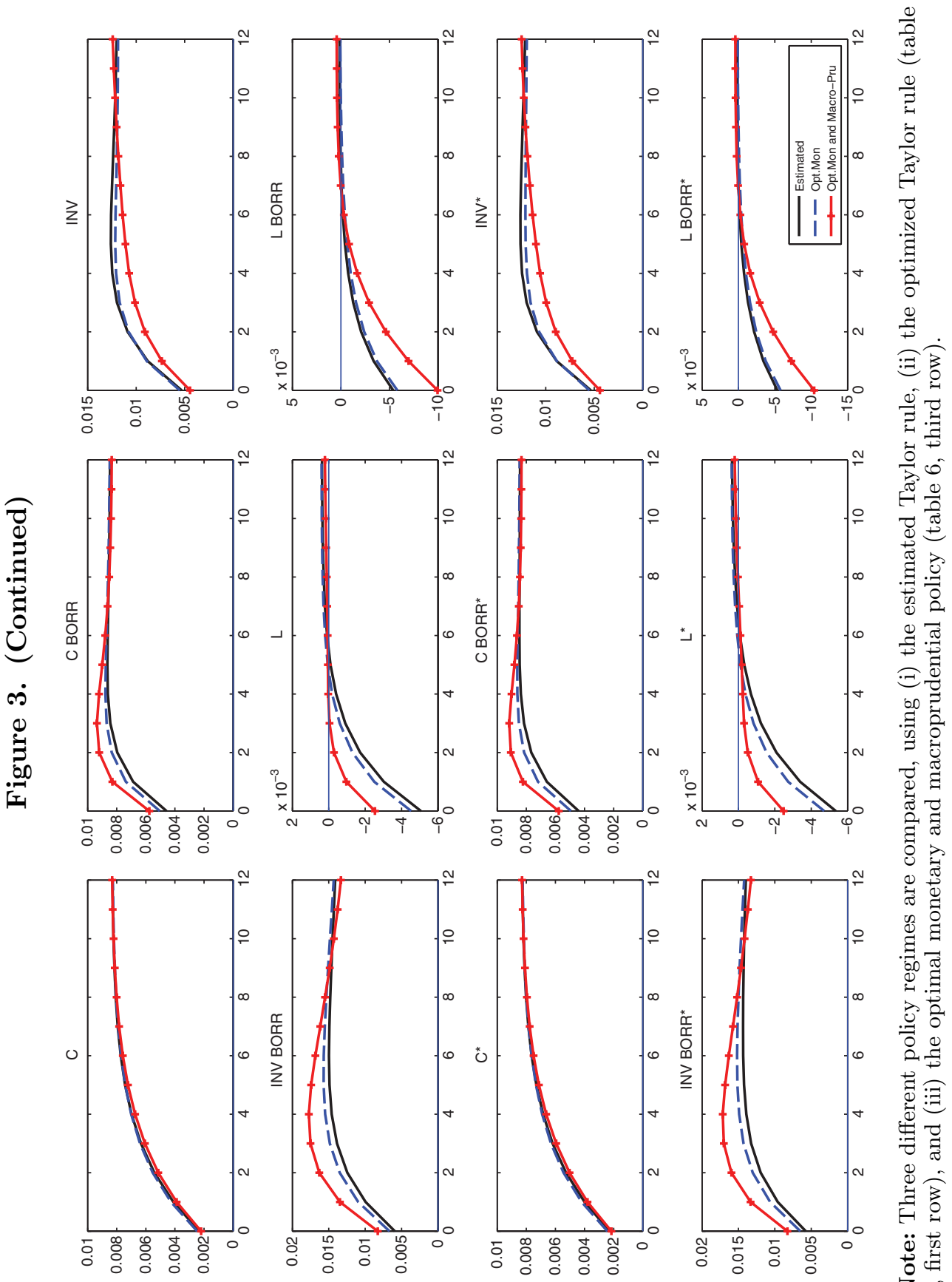

0

풍

迅

胥

要

蛋

$\Im$ 융

.

ठี

:

일

늉

ข

है घ

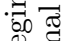

․․

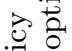

용

륭

虰

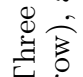

E.

苛葛 
new level. CPI inflation falls in both areas due to the decline in real marginal costs, while (nominal and real) house prices increase. Interestingly, under the estimated rule, credit-to-GDP falls, even though both quantities (credit and GDP) increase. The lendingdeposit spread changes only slightly, reflecting minimal movements in the LTV ratios.

Optimal monetary policy aims at bringing CPI inflation back to target so that the ECB cuts nominal interest rates and CPI inflation falls to a lesser extent. Moreover, most real variables display less volatility and a faster transition to their new steady-state values. The macroprudential policy aims at addressing the decline of the credit-to-GDP ratio by allowing banks to lend more. As a result, the credit-to-GDP ratio falls by much less and the lending-deposit rate becomes more volatile. This generates a higher countercyclical response of the lending rate, which finally increases the volatility of consumption and residential investment by borrowers. Because they have access to cheap credit, borrowers spend more and supply less labor, making hours worked for borrowers also more volatile, which further adds to their welfare cost. On the other hand, savers still face a smooth consumption and investment plan. By picking up the labor slack left by borrowers, their overall labor supply is less volatile, contributing to their welfare increase.

Hence, in a model with a microfounded behavior of the lendingdeposit spread, and the welfare function, we find a similar result to Kannan, Rabanal, and Scott (2012), who use ad hoc lendingdeposit spreads and welfare functions. Macroprudential policies that "lean against the wind" improve welfare when it is optimal to reduce the countercyclical behavior of the spread, as is the case of housing demand or risk shocks. However, under technology shocks, mechanical responses to the credit-to-GDP ratio will actually increase the countercyclical behavior of the spread, leading to an increased volatility of spending by borrowers, and hurting their welfare, even when the impact on aggregate variables such as real GDP or CPI inflation is quantitatively very small.

We conduct an additional robustness result by looking at the optimal response of monetary and macroprudential policies if the policymakers were able to identify the source of the shock. To that end, we simulate the model with either technology shocks only (including all sectors and countries and the unit-root shock), 
Table 7. Optimal Monetary and Macroprudential Policy, Conditional on Shocks

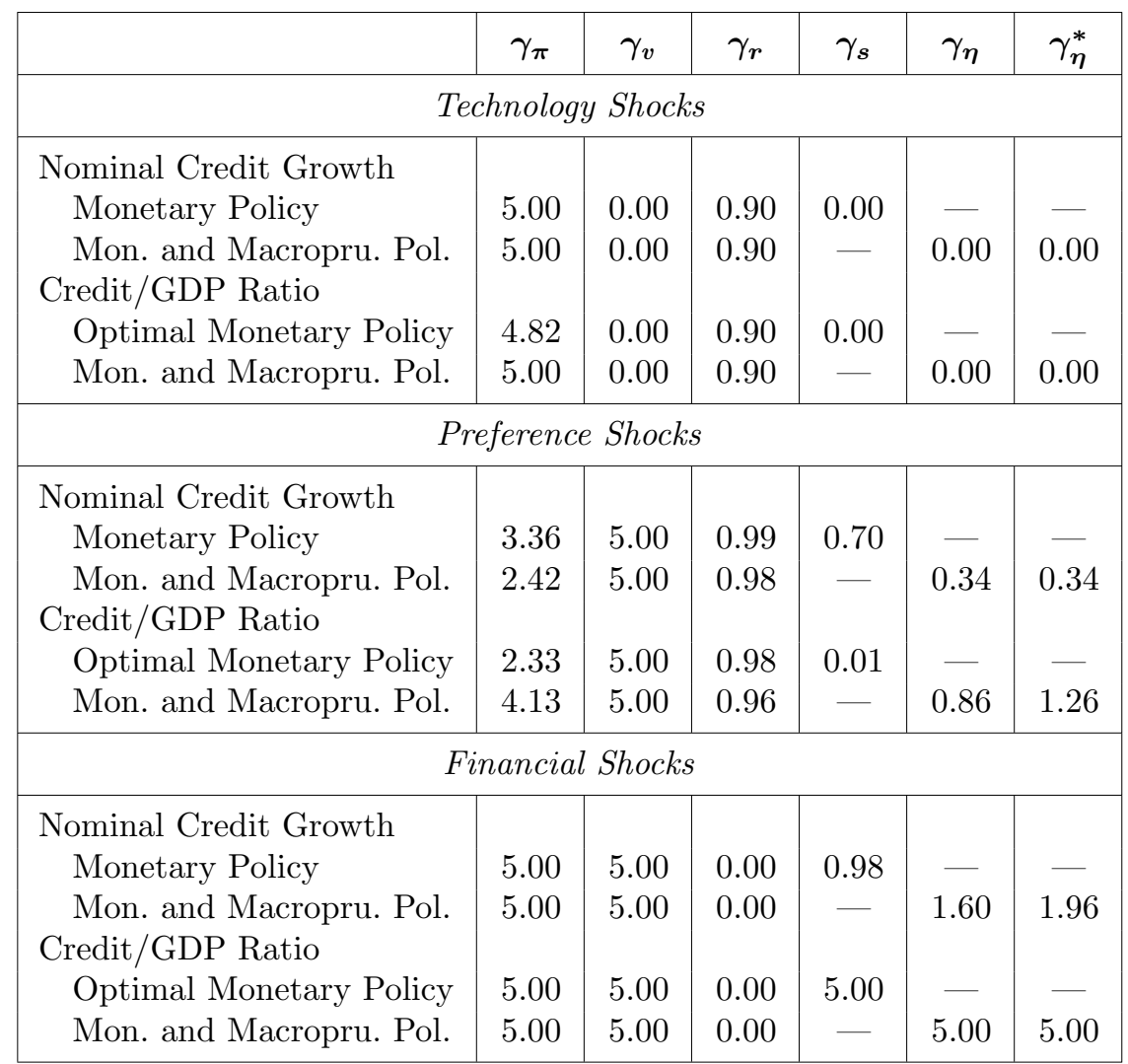

preference shocks only (including all countries and sectors), and financial shocks only (including the housing quality risk shock and the risk premium shock across countries). The optimal responses are quite different when the monetary and macroprudential authorities can identify the source of the shock (table 7). A key difference, which we identified in the impulse response analysis, is that the optimal monetary and macroprudential response to any credit aggregate becomes zero under technology shocks. As we already saw from figure 3, including macroprudential policies when technology shocks are present reduced welfare of borrowers by inducing too 
much volatility in the lending-deposit spread. However, when financial and demand shocks hit the economy, the optimal macroprudential responses calls for responding to credit aggregates to offset their effects.

\section{Conclusions}

In this paper, we have studied the optimal mix of monetary and macroprudential policy rules in an estimated DSGE model of the euro area. We have found that in a variety of scenarios and calibrations, the introduction of a macroprudential rule would help in reducing macroeconomic volatility and hence in improving EMUwide welfare. At the same time, macroprudential policies "lend a hand" to monetary policy by reducing accelerator effects and, thus, requiring smaller responses of the nominal interest. We have also shown that the effects of macroprudential regulations can affect savers and borrowers differently. The policy that improves welfare in the EMU the most - which would have macroprudential policies respond to the credit-to-GDP ratio - reduces the welfare of borrowers by inducing a too-countercyclical response of the lendingdeposit spread. A welfare improvement for all citizens in the EMU is achieved when macroprudential policies respond to nominal credit growth.

\section{Appendix 1. Data and Sources}

Since we distinguish between two regions of the euro area, data for the core are obtained by aggregating data for France and Germany, while data for Greece, Ireland, Italy, Portugal, and Spain are combined for the periphery. The aggregation is done by computing weighted averages, taking into account the relative economic size of the countries (measured by nominal GDP). Some of the series start later than 1995:Q4 or end earlier than 2011:Q4. If this is the case, aggregation for these quarters only takes into account available data, while weights are adjusted accordingly. All data are seasonally adjusted in case this was not done by the original source. Finally, all data are demeaned. 
Inflation: Quarter-on-quarter log-differences in the Harmonised Index of Consumer Prices (HICP), not seasonally adjusted by the source. Source: ECB.

Change in House-Price Data: Quarter-on-quarter log-differences in real housing prices. All data, except for Greece and Portugal, are provided by the OECD. Greek and Portuguese data are provided by the BIS. All OECD data are seasonally adjusted by the source, while BIS data are not. Portuguese data are only available on a monthly basis and are transformed to a quarterly frequency by taking averages. Data for Italy already end in 2011:Q3.

Real Private Consumption: Final consumption of households and non-profit institutions serving households (NPISH), seasonally adjusted by the source. Source: Eurostat.

Real Residential Investment: Gross fixed capital formation in construction work for housing, seasonally adjusted by the source. Data for Ireland are only available on an annual basis, while data for Greece are only available from 2000 onwards on an annual basis. Both data are interpolated to obtain quarterly values. Source: Eurostat.

ECB Interest Rate: Three-month Euribor. Source: ECB.

Household Outstanding Debt: Data seasonally adjusted by the source. Data for Greece start in 1997:Q4, for Ireland in 2002:Q1, and for Italy in 1997:Q1. Source: Eurostat.

Nominal GDP for computing the weights used in the aggregation is taken from the IMF International Financial Statistics (IFS). These data are also used to calculate the size of the core and periphery region. Furthermore, for the calibration we use import data (source: IMF Direction of Trade Statistics) and data on nominal household consumption (source: IFS) to compute the fraction of imported goods. The size of the non-durable sector is calculated as a ratio of gross value added by the construction sector to that of all branches (source: Eurostat). The steady-state ratio of defaults is calculated using non-performing loans as a percent of total loans for the euro area between 2000 and 2011 (source: World Bank World Development Indicators database). 


\section{Appendix 2. Linearized Conditions}

In this section we present all log-linear conditions of the model. Uppercase variables denote steady-state values, lowercase variables denote log-linear deviations from steady-state values, and foreign variables are indicated with asterisks. Additionally, we make use of the following definitions:

- $Q_{t}$ denotes the relative price of durables in term of nondurables $\left(Q_{t} \equiv \frac{P_{t}^{D}}{P_{t}^{C}}\right)$.

- $\tilde{w}_{t}^{i}$ denotes the deviation of the real wages (nominal wages $W_{t}^{i}$ divided by the CPI index $P_{t}^{C}$, for $\left.i=\{C, D\}\right)$ from their steady-state values.

- $\tilde{S}_{t}^{B}$ denotes real domestic debt expressed in terms of nondurable goods $\left(\tilde{S}_{t}^{B} \equiv \frac{S_{t}^{B}}{P_{t}^{C}}\right)$.

- $b_{t}$ denotes the deviations of foreign assets as a percent of steady-state non-durable output from its steady-state value of zero $\left(b_{t} \equiv \frac{B_{t}}{P_{t}^{C} Y^{C}}\right)$.

- $\hat{\bar{\omega}}_{t}^{i}$ and $\hat{\sigma}_{\omega, t}$ denote the deviations from their steady-state values for the threshold $\bar{\omega}_{t}^{i}$ and the variance $\bar{\sigma}_{\omega, t}$, respectively (for $i=\{a, p\}$ ).

- The terms of trade is given by $T_{t}=\frac{P_{F, t}}{P_{H, t}}$.

- The average interest rate of those who default is defined as $R_{t}^{D}=G\left(\bar{\omega}_{t-1}^{P}, \sigma_{\omega, t-1}\right) P_{t}^{D} D_{t}^{B} / S_{t-1}^{B}$.

- Aggregate non-durable consumption is given by $C_{t}^{T O T}=$ $\lambda C_{t}+(1-\lambda) C_{t}^{B}$.

In addition, since the model includes a unit-root shock in technology, the following variables in both countries inherit the same unit-root behavior:

- consumption of non-durables (by agent and aggregate, including domestically produced and imported): $C_{t}, C_{t}^{B}, C_{t}^{T O T}$, $C_{H, t}, C_{F, t}$

- residential investment and the housing stock of both borrowers and savers: $I_{t}, I_{t}^{B}, D_{t}, D_{t}^{B}$

- real wages in both sectors: $W_{t}^{C}$ and $W_{t}^{D}$ 
- the production of durable and non-durable goods: $Y_{t}^{C}$ and $Y_{t}^{D}$, and real GDP $Y_{t}$

- real credit $\tilde{S}_{t}^{B}$

Hence, we normalize all these real variables by the EMU level of technology $A_{t}$. For these variables, lowercase variables denote deviations from steady-state values of normalized variables. That is, $c_{t}=$ $\log \left(C_{t} / A_{t}\right)-\log (\overline{C / A})$ and so on. Foreign country variables are normalized in the same way. For instance, $c_{t}^{*}=\log \left(C_{t}^{*} / A_{t}\right)-\log \left(\overline{C^{*} / A}\right)$.

\section{Home Country}

From the optimal decision by savers we get the following 27

$$
\begin{aligned}
q_{t} & +\xi_{t}^{C}-\frac{c_{t}-\varepsilon\left(c_{t-1}-\varepsilon_{t}^{A}\right)}{1-\varepsilon}+\psi\left(i_{t}-i_{t-1}+\varepsilon_{t}^{A}\right) \\
& =E_{t} \varrho_{t+1}+\beta \psi\left(E_{t} i_{t+1}-i_{t}\right)
\end{aligned}
$$

where $\psi=\digamma^{\prime \prime}($.$) and \varrho_{t}$ is the normalized Lagrange multiplier associated with the law of motion of the housing stock (10) for savers, and

$$
\begin{gathered}
{[1-\beta(1-\delta)]\left(\xi_{t}^{D}-d_{t}\right)=\varrho_{t}-\beta(1-\delta) E_{t} \varrho_{t+1}} \\
\varepsilon\left(\Delta c_{t}+\varepsilon_{t}^{A}\right)=E_{t} \Delta c_{t+1}-(1-\varepsilon)\left(r_{t}+E_{t} \Delta \xi_{t+1}^{C}-E_{t} \Delta p_{t+1}^{C}\right) .
\end{gathered}
$$

The labor supply schemes to the non-durable and durable sectors are

$$
\begin{gathered}
{\left[\left(\varphi-\iota_{L}\right) \alpha+\iota_{L}\right] l_{t}^{C}+\left(\varphi-\iota_{L}\right)(1-\alpha) l_{t}^{D}} \\
=\tilde{w}_{t}^{C}+\xi_{t}^{C}-\frac{c_{t}-\varepsilon\left(c_{t-1}-\varepsilon_{t}^{A}\right)}{1-\varepsilon} \\
{\left[\left(\varphi-\iota_{L}\right)(1-\alpha)+\iota_{L}\right] l_{t}^{D}+\left(\varphi-\iota_{L}\right) \alpha l_{t}^{C}} \\
=\tilde{w}_{t}^{D}+\xi_{t}^{C}-\frac{c_{t}-\varepsilon\left(c_{t-1}-\varepsilon_{t}^{A}\right)}{1-\varepsilon} .
\end{gathered}
$$

\footnotetext{
${ }^{27}$ Since all households behave the same way, we henceforth drop the $j$ super-
} script. 
The same conditions for borrowers are

$$
\begin{aligned}
q_{t} & +\xi_{t}^{C}-\frac{c_{t}^{B}-\varepsilon^{B}\left(c_{t-1}^{B}-\varepsilon_{t}^{A}\right)}{1-\varepsilon^{B}}+\psi\left(i_{t}^{B}-i_{t-1}^{B}+\varepsilon_{t}^{A}\right) \\
& =E_{t} \varrho_{t+1}^{B}+\beta^{B} \psi\left(E_{t} i_{t+1}^{B}-i_{t}^{B}\right),
\end{aligned}
$$

with $\varrho_{t}^{B}$ being the Lagrange multiplier associated with the law of motion of the housing stock (10) for borrowers, and

$$
\begin{aligned}
& {\left[1-\beta^{B}(1-\delta)\right]\left(\xi_{t}^{D}-d_{t}^{B}\right)=\varrho_{t}^{B}-\beta^{B}(1-\delta) E_{t} \varrho_{t+1}^{B}} \\
& \varepsilon^{B}\left(\Delta c_{t}^{B}+\varepsilon_{t}^{A}\right) \\
& =E_{t} \Delta c_{t+1}^{B}-\left(1-\varepsilon^{B}\right)\left(\beta^{B} R^{D} E_{t} r_{t+1}^{D}+E_{t} \Delta \xi_{t+1}^{C}-E_{t} \Delta p_{t+1}^{C}\right) \\
& \quad-\left(1-\varepsilon^{B}\right) \beta^{B} R^{L}\left[1-F\left(\bar{\omega}, \sigma_{\omega}\right)\right] \\
& \quad \times\left(r_{t}^{L}-\frac{F_{\omega}\left(\bar{\omega}, \sigma_{\omega}\right) \bar{\omega}}{1-F\left(\bar{\omega}, \sigma_{\omega}\right)} \hat{\bar{\omega}}_{t}^{a}-\frac{F_{\sigma_{\omega}}\left(\bar{\omega}, \sigma_{\omega}\right) \sigma_{\omega}}{1-F\left(\bar{\omega}, \sigma_{\omega}\right)} \hat{\sigma}_{\omega, t}\right)
\end{aligned}
$$

where the interest rate for those who default is given by

$$
\begin{aligned}
r_{t}^{D}= & d_{t}^{B}-\tilde{s}_{t-1}^{B}+\frac{G_{\omega}\left(\bar{\omega}, \sigma_{\omega}\right) \bar{\omega}}{G\left(\bar{\omega}, \sigma_{\omega}\right)} \hat{\bar{\omega}}_{t-1}^{p}+\frac{G_{\sigma_{\omega}}\left(\bar{\omega}, \sigma_{\omega}\right) \sigma_{\omega}}{G\left(\bar{\omega}, \sigma_{\omega}\right)} \hat{\sigma}_{\omega, t-1} \\
& +q_{t}+\Delta p_{t}^{C}+\varepsilon_{t}^{A} .
\end{aligned}
$$

The labor supply schemes to the non-durable and durable sectors are

$$
\begin{aligned}
& {\left[\left(\varphi-\iota_{L}\right) \alpha+\iota_{L}\right] l_{t}^{B, C}+\left(\varphi-\iota_{L}\right)(1-\alpha) l_{t}^{B, D}} \\
& \quad=\tilde{w}_{t}^{C}+\xi_{t}^{C}-\frac{c_{t}^{B}-\varepsilon^{B}\left(c_{t-1}^{B}-\varepsilon_{t}^{A}\right)}{1-\varepsilon^{B}}, \\
& {\left[\left(\varphi-\iota_{L}\right)(1-\alpha)+\iota_{L}\right] l_{t}^{B, D}+\left(\varphi-\iota_{L}\right) \alpha l_{t}^{B, C}} \\
& \quad=\tilde{w}_{t}^{D}+\xi_{t}^{C}-\frac{c_{t}^{B}-\varepsilon^{B}\left(c_{t-1}^{B}-\varepsilon_{t}^{A}\right)}{1-\varepsilon^{B}} .
\end{aligned}
$$


The budget constraint of borrowers is

$$
\begin{aligned}
& C^{B} c_{t}^{B}+\delta D^{B}\left(q_{t}+i_{t}^{B}\right)+R^{D} \tilde{S}^{B}\left[r_{t}^{D}+\tilde{s}_{t-1}^{B}-\Delta p_{t}^{C}-\varepsilon_{t}^{A}\right] \\
& +\left[1-F\left(\bar{\omega}, \sigma_{\omega}\right)\right] R^{L} \tilde{S}^{B}\left[r_{t-1}^{L}+\tilde{s}_{t-1}^{B}-\Delta p_{t}^{C}-\varepsilon_{t}^{A}\right] \\
& -\left[1-F\left(\bar{\omega}, \sigma_{\omega}\right)\right] R^{L} \tilde{S}^{B}\left[\frac{F_{\omega}\left(\bar{\omega}, \sigma_{\omega}\right) \bar{\omega}}{1-F\left(\bar{\omega}, \sigma_{\omega}\right)} \hat{\bar{\omega}}_{t-1}^{p}+\frac{F_{\sigma_{\omega}}\left(\bar{\omega}, \sigma_{\omega}\right) \sigma_{\omega}}{1-F\left(\bar{\omega}, \sigma_{\omega}\right)} \hat{\sigma}_{\omega, t-1}\right] \\
& =\tilde{S}^{B} \tilde{s}_{t}^{B}+\alpha W L^{B}\left(\tilde{w}_{t}^{C}+l_{t}^{B, C}\right)+(1-\alpha) W L^{B}\left(\tilde{w}_{t}^{D}+l_{t}^{B, D}\right) .
\end{aligned}
$$

The lending rate for borrowers is determined by the participation constraint of financial intermediaries:

$$
\begin{aligned}
& \frac{1}{\beta} \tilde{S}^{B}\left(r_{t}+\tilde{s}_{t}^{B}+\eta_{t}\right) \\
& =(1-\mu) D^{B} G\left(\bar{\omega}, \sigma_{\omega}\right)\left[\frac{G_{\omega}\left(\bar{\omega}, \sigma_{\omega}\right) \bar{\omega}}{G\left(\bar{\omega}, \sigma_{\omega}\right)} \hat{\bar{\omega}}_{t}^{a}+\frac{G_{\sigma_{\omega}}\left(\bar{\omega}, \sigma_{\omega}\right) \sigma_{\omega}}{G\left(\bar{\omega}, \sigma_{\omega}\right)} \hat{\sigma}_{\omega, t}\right] \\
& \quad+(1-\mu) D^{B} G\left(\bar{\omega}, \sigma_{\omega}\right)\left[E_{t} q_{t+1}+E_{t} d_{t+1}^{B}+E_{t} \Delta p_{t+1}^{C}\right] \\
& \quad+\left[1-F\left(\bar{\omega}, \sigma_{\omega}\right)\right] R^{L} \tilde{S}^{B} \\
& \quad \times\left[r_{t}^{L}+\tilde{s}_{t}^{B}-\frac{F_{\omega}\left(\bar{\omega}, \sigma_{\omega}\right) \bar{\omega}}{1-F\left(\bar{\omega}, \sigma_{\omega}\right)} \hat{\bar{\omega}}_{t}^{a}-\frac{F_{\sigma_{\omega}}\left(\bar{\omega}, \sigma_{\omega}\right) \sigma_{\omega}}{1-F\left(\bar{\omega}, \sigma_{\omega}\right)} \hat{\sigma}_{\omega, t}\right] .
\end{aligned}
$$

The ex ante and ex post default threshold is

$$
\begin{aligned}
\hat{\bar{\omega}}_{t}^{a}+E_{t}\left[q_{t+1}+d_{t+1}^{B}\right] & =r_{t}^{L}+\tilde{s}_{t}^{B}-E_{t} \Delta p_{t+1}^{C}, \\
\hat{\bar{\omega}}_{t-1}^{p}+q_{t}+d_{t}^{B} & =r_{t-1}^{L}+\tilde{s}_{t-1}^{B}-\Delta p_{t}^{C}-\varepsilon_{t}^{A} .
\end{aligned}
$$

The evolution of domestic and imported non-durable consumption is

$$
\begin{gathered}
c_{H, t}=\iota_{C}(1-\tau) t_{t}+c_{t}^{T O T}, \\
c_{F, t}=-\iota_{C} \tau t_{t}+c_{t}^{T O T},
\end{gathered}
$$

where aggregate non-durable consumption is

$$
\left[\lambda C+(1-\lambda) C^{B}\right] c_{t}^{T O T}=\lambda C c_{t}+(1-\lambda) C^{B} c_{t}^{B}
$$


The production functions are given by

$$
\begin{aligned}
& y_{t}^{C}=z_{t}^{C}+l_{t}^{C, T O T}, \\
& y_{t}^{D}=z_{t}^{D}+l_{t}^{D, T O T},
\end{aligned}
$$

where total hours in each sector are given by

$$
\begin{aligned}
{\left[\lambda L^{C}+(1-\lambda) L^{B, C}\right] l_{t}^{C, T O T} } & =\lambda L^{C} l_{t}^{C}+(1-\lambda) L^{B, C} l_{t}^{B, C}, \\
{\left[\lambda L^{D}+(1-\lambda) L^{B, D}\right] l_{t}^{D, T O T} } & =\lambda L^{D} l_{t}^{D}+(1-\lambda) L^{B, D} l_{t}^{B, D} .
\end{aligned}
$$

The CPI is given by

$$
\Delta p_{t}^{C}=\tau \Delta p_{H, t}+(1-\tau) \Delta p_{F, t} .
$$

The relative price of housing is

$$
q_{t}=q_{t-1}+\Delta p_{t}^{D}-\Delta p_{t}^{C},
$$

and the pricing equations are given by

$$
\begin{aligned}
& \Delta p_{t}^{H}-\varphi_{C} \Delta p_{t-1}^{H} \\
& \quad=\beta E_{t}\left(\Delta p_{t+1}^{H}-\varphi_{C} \Delta p_{t}^{H}\right)+\kappa^{C}\left[\tilde{w}_{t}^{C}+(1-\tau) t_{t}-z_{t}^{C}\right],
\end{aligned}
$$

where $\kappa^{C}=\frac{\left(1-\theta_{C}\right)\left(1-\beta \theta_{C}\right)}{\theta_{C}}$, and

$$
\Delta p_{t}^{D}-\varphi_{D} \Delta p_{t-1}^{D}=\beta E_{t}\left(\Delta p_{t+1}^{D}-\varphi_{D} \Delta p_{t}^{D}\right)+\kappa^{D}\left[\tilde{w}_{t}^{D}-q_{t}-z_{t}^{D}\right]
$$

where $\kappa^{D}=\frac{\left(1-\theta_{D}\right)\left(1-\beta \theta_{D}\right)}{\theta_{D}}$.

The market clearing conditions for the non-durable goods sector reads as follows:

$$
y_{t}^{C}=\tau c_{H, t}+\frac{(1-n)\left(1-\tau^{*}\right)}{n} c_{H, t}^{*} .
$$

Aggregate investment expenditures equal production of investment goods:

$$
y_{t}^{D}=\frac{\lambda \delta D i_{t}+(1-\lambda) \delta D^{B} i_{t}^{B}}{\lambda \delta D+(1-\lambda) \delta D^{B}}
$$


and the law of motion of the two types of housing stocks is given by

$$
\begin{aligned}
d_{t} & =(1-\delta) d_{t-1}+\delta i_{t-1}-\varepsilon_{t}^{A} \\
d_{t}^{B} & =(1-\delta) d_{t-1}^{B}+\delta i_{t-1}^{B}-\varepsilon_{t}^{A}
\end{aligned}
$$

Aggregated output is given by

$$
y_{t}=\alpha y_{t}^{C}+(1-\alpha)\left(y_{t}^{D}+q_{t}\right)
$$

\section{Foreign Country}

Here, we present the conditions of the model for the foreign country. From the optimal decision of savers we get the following:

$$
\begin{gathered}
q_{t}^{*}+\xi_{t}^{C^{*}}-\frac{c_{t}^{*}-\varepsilon\left(c_{t-1}^{*}-\varepsilon_{t}^{A}\right)}{1-\varepsilon}+\psi\left(i_{t}^{*}-i_{t-1}^{*}+\varepsilon_{t}^{A}\right) \\
=E_{t} \varrho_{t+1}^{*}+\beta \psi\left(E_{t} i_{t+1}^{*}-i_{t}^{*}\right) \\
{[1-\beta(1-\delta)]\left(\xi_{t}^{D^{*}}-d_{t}^{*}\right)=\varrho_{t}^{*}-\beta(1-\delta) E_{t} \varrho_{t+1}^{*},} \\
\varepsilon\left(\Delta c_{t}^{*}+\varepsilon_{t}^{A}\right)=E_{t} \Delta c_{t+1}^{*}-(1-\varepsilon)\left(r_{t}^{*}+E_{t} \Delta \xi_{t+1}^{C^{*}}-E_{t} \Delta p_{t+1}^{C^{*}}\right), \\
{\left[\left(\varphi-\iota_{L}\right) \alpha+\iota_{L}\right] l_{t}^{C^{*}}+\left(\varphi-\iota_{L}\right)(1-\alpha) l_{t}^{D^{*}}} \\
=\tilde{w}_{t}^{C^{*}}+\xi_{t}^{C^{*}}-\frac{c_{t}^{*}-\varepsilon\left(c_{t-1}^{*}-\varepsilon_{t}^{A}\right)}{1-\varepsilon} \\
{\left[\left(\varphi-\iota_{L}\right)(1-\alpha)+\iota_{L}\right] l_{t}^{D^{*}}+\left(\varphi-\iota_{L}\right) \alpha l_{t}^{C^{*}}} \\
=\tilde{w}_{t}^{D^{*}}+\xi_{t}^{C^{*}}-\frac{c_{t}^{*}-\varepsilon\left(c_{t-1}^{*}-\varepsilon_{t}^{A}\right)}{1-\varepsilon} .
\end{gathered}
$$

The same conditions for borrowers are

$$
\begin{aligned}
& q_{t}^{*}+\xi_{t}^{C^{*}}-\frac{c_{t}^{B^{*}}-\varepsilon^{B}\left(c_{t-1}^{B^{*}}-\varepsilon_{t}^{A}\right)}{1-\varepsilon^{B^{*}}}+\psi\left(i_{t}^{B^{*}}-i_{t-1}^{B^{*}}+\varepsilon_{t}^{A}\right) \\
& \quad=E_{t} \varrho_{t+1}^{B^{*}}+\beta^{B} \psi\left(E_{t} i_{t+1}^{B^{*}}-i_{t}^{B^{*}}\right), \\
& {\left[1-\beta^{B}(1-\delta)\right]\left(\xi_{t}^{D^{*}}-d_{t}^{B^{*}}\right)=\varrho_{t}^{B^{*}}-\beta^{B}(1-\delta) E_{t} \varrho_{t+1}^{B^{*}},}
\end{aligned}
$$




$$
\begin{gathered}
\varepsilon^{B}\left(\Delta c_{t}^{B^{*}}+\varepsilon_{t}^{A}\right) \\
=E_{t} \Delta c_{t+1}^{B^{*}}-\left(1-\varepsilon^{B}\right)\left(\beta^{B} R^{D^{*}} E_{t} r_{t+1}^{D^{*}}+E_{t} \Delta \xi_{t+1}^{C^{*}}-E_{t} \Delta p_{t+1}^{C^{*}}\right) \\
-\left(1-\varepsilon^{B}\right) \beta^{B} R^{L *}\left[1-F\left(\bar{\omega}, \sigma_{\omega}\right)\right] \\
\quad \times\left(r_{t}^{L *}-\frac{F_{\omega}\left(\bar{\omega}, \sigma_{\omega}\right) \bar{\omega}}{1-F\left(\bar{\omega}, \sigma_{\omega}\right)} \hat{\bar{\omega}}_{t}^{a *}-\frac{F_{\sigma_{\omega}}\left(\bar{\omega}, \sigma_{\omega}\right) \sigma_{\omega}}{1-F\left(\bar{\omega}, \sigma_{\omega}\right)} \hat{\sigma}_{\omega, t}^{*}\right) \\
r_{t}^{D^{*}}=d_{t}^{B^{*}}-\tilde{s}_{t-1}^{B^{*}}+\frac{G_{\omega}\left(\bar{\omega}, \sigma_{\omega}\right) \bar{\omega}}{G\left(\bar{\omega}, \sigma_{\omega}\right)} \hat{\bar{\omega}}_{t-1}^{p *}+\frac{G_{\sigma_{\omega}}\left(\bar{\omega}, \sigma_{\omega}\right) \sigma_{\omega}}{G\left(\bar{\omega}, \sigma_{\omega}\right)} \hat{\sigma}_{\omega, t-1}^{*} \\
+q_{t}^{*}+\Delta p_{t}^{C^{*}}+\varepsilon_{t}^{A}, \\
{\left[\left(\varphi-\iota_{L}\right) \alpha+\iota_{L}\right] l_{t}^{B, C^{*}}+\left(\varphi-\iota_{L}\right)(1-\alpha) l_{t}^{B, D^{*}}} \\
=\tilde{w}_{t}^{C^{*}}+\xi_{t}^{C^{*}}-\frac{c_{t}^{B^{*}}-\varepsilon^{B}\left(c_{t-1}^{B^{*}}-\varepsilon_{t}^{A}\right)}{1-\varepsilon^{B}} \\
{\left[\left(\varphi-\iota_{L}\right)(1-\alpha)+\iota_{L}\right] l_{t}^{B, D^{*}}+\left(\varphi-\iota_{L}\right) \alpha l_{t}^{B, C^{*}}} \\
=\tilde{w}_{t}^{D^{*}}+\xi_{t}^{C^{*}}-\frac{c_{t}^{B^{*}}-\varepsilon^{B}\left(c_{t-1}^{B^{*}}-\varepsilon_{t}^{A}\right)}{1-\varepsilon^{B}} .
\end{gathered}
$$

The budget constraint of borrowers is

$$
\begin{aligned}
& C^{B *} c_{t}^{B *}+\delta D^{B *}\left(q_{t}^{*}+i_{t}^{B *}\right)+R^{D *} \tilde{S}^{B *}\left[r_{t}^{D *}+\tilde{s}_{t-1}^{B *}-\Delta p_{t}^{C *}-\varepsilon_{t}^{A}\right] \\
& +\left[1-F\left(\bar{\omega}, \sigma_{\omega}\right)\right] R^{L *} \tilde{S}^{B *}\left[r_{t-1}^{L *}+\tilde{s}_{t-1}^{B *}-\Delta p_{t}^{C *}-\varepsilon_{t}^{A}\right] \\
& -\left[1-F\left(\bar{\omega}, \sigma_{\omega}\right)\right] R^{L *} \tilde{S}^{B *}\left[\frac{F_{\omega}\left(\bar{\omega}, \sigma_{\omega}\right) \bar{\omega}}{1-F\left(\bar{\omega}, \sigma_{\omega}\right)} \hat{\bar{\omega}}_{t-1}^{p *}+\frac{F_{\sigma_{\omega}}\left(\bar{\omega}, \sigma_{\omega}\right) \sigma_{\omega}}{1-F\left(\bar{\omega}, \sigma_{\omega}\right)} \hat{\sigma}_{\omega, t-1}^{*}\right] \\
& =\tilde{S}^{B *} \tilde{s}_{t}^{B *}+\alpha W^{*} L^{B *}\left(\tilde{w}_{t}^{C *}+l_{t}^{B, C *}\right)+(1-\alpha) W^{*} L^{B *}\left(\tilde{w}_{t}^{D *}+l_{t}^{B, D *}\right) .
\end{aligned}
$$

The participation constraint of financial intermediaries is

$$
\begin{aligned}
& \frac{1}{\beta} \tilde{S}^{B^{*}}\left(r_{t}^{*}+\tilde{s}_{t}^{B^{*}}+\eta_{t}^{*}\right) \\
& \quad=(1-\mu) D^{B^{*}} G\left(\bar{\omega}, \sigma_{\omega}\right)\left[\frac{G_{\omega}\left(\bar{\omega}, \sigma_{\omega}\right) \bar{\omega}}{G\left(\bar{\omega}, \sigma_{\omega}\right)} \hat{\bar{\omega}}_{t}^{a *}+\frac{G_{\sigma_{\omega}}\left(\bar{\omega}, \sigma_{\omega}\right) \sigma_{\omega}}{G\left(\bar{\omega}, \sigma_{\omega}\right)} \hat{\sigma}_{\omega, t}^{*}\right]
\end{aligned}
$$




$$
\begin{aligned}
& +(1-\mu) D^{B^{*}} G\left(\bar{\omega}, \sigma_{\omega}\right)\left[E_{t} q_{t+1}^{*}+E_{t} d_{t+1}^{B^{*}}+E_{t} \Delta p_{t+1}^{C^{*}}\right] \\
& +\left[1-F\left(\bar{\omega}, \sigma_{\omega}\right)\right] R^{L *} \tilde{S}^{B^{*}} \\
& \times\left[r_{t}^{L *}+\tilde{s}_{t}^{B^{*}}-\frac{F_{\omega}\left(\bar{\omega}, \sigma_{\omega}\right) \bar{\omega}}{1-F\left(\bar{\omega}, \sigma_{\omega}\right)} \hat{\bar{\omega}}_{t}^{a *}-\frac{F_{\sigma_{\omega}}\left(\bar{\omega}, \sigma_{\omega}\right) \sigma_{\omega}}{1-F\left(\bar{\omega}, \sigma_{\omega}\right)} \hat{\sigma}_{\omega, t}^{*}\right] .
\end{aligned}
$$

The ex ante and ex post default threshold is

$$
\begin{aligned}
\hat{\bar{\omega}}_{t}^{a *}+E_{t}\left[q_{t+1}^{*}+d_{t+1}^{B^{*}}\right] & =r_{t}^{L *}+\tilde{s}_{t}^{B^{*}}-E_{t} \Delta p_{t+1}^{C^{*}}, \\
\hat{\bar{\omega}}_{t-1}^{p *}+q_{t}^{*}+d_{t}^{B^{*}} & =r_{t-1}^{L *}+\tilde{s}_{t-1}^{B^{*}}-\Delta p_{t}^{C^{*}}-\varepsilon_{t}^{A} .
\end{aligned}
$$

The evolution of domestic and imported non-durable consumption is

$$
\begin{array}{r}
c_{H, t}^{*}=\iota_{C} \tau^{*} t_{t}+c_{t}^{T O T^{*}}, \\
c_{F, t}^{*}=-\iota_{C}\left(1-\tau^{*}\right) t_{t}+c_{t}^{T O T^{*}},
\end{array}
$$

where aggregate non-durable consumption is

$$
\left[\lambda C^{*}+(1-\lambda) C^{B^{*}}\right] c_{t}^{T O T^{*}}=\lambda C^{*} c_{t}^{*}+(1-\lambda) C^{B^{*}} c_{t}^{B^{*}} .
$$

The production functions are given by

$$
\begin{aligned}
& y_{t}^{C^{*}}=z_{t}^{C^{*}}+l_{t}^{C, T O T^{*}}, \\
& y_{t}^{D^{*}}=z_{t}^{D^{*}}+l_{t}^{D, T O T^{*}},
\end{aligned}
$$

where total hours in each sector are given by

$$
\begin{gathered}
{\left[\lambda L^{C^{*}}+(1-\lambda) L^{B, C^{*}}\right] l_{t}^{C, T O T^{*}}=\lambda L^{C^{*}} l_{t}^{C^{*}}+(1-\lambda) L^{B, C^{*}} l_{t}^{B, C^{*}},} \\
{\left[\lambda L^{D^{*}}+(1-\lambda) L^{B, D^{*}}\right] l_{t}^{D, T O T^{*}}=\lambda L^{D^{*}} l_{t}^{D^{*}}+(1-\lambda) L^{B, D^{*}} l_{t}^{B, D^{*}} .}
\end{gathered}
$$

The CPI is

$$
\Delta p_{t}^{C^{*}}=\left(1-\tau^{*}\right) \Delta p_{H, t}+\tau^{*} \Delta p_{F, t} .
$$


The relative price of housing is

$$
q_{t}^{*}=q_{t-1}^{*}+\Delta p_{t}^{D^{*}}-\Delta p_{t}^{C^{*}},
$$

and the pricing equations are given by

$$
\begin{aligned}
& \Delta p_{t}^{F}-\varphi_{C}^{*} \Delta p_{t-1}^{F} \\
& \quad=\beta E_{t}\left(\Delta p_{t+1}^{F}-\varphi_{C}^{*} \Delta p_{t}^{F}\right)+\kappa^{C^{*}}\left[\tilde{w}_{t}^{C^{*}}-\left(1-\tau^{*}\right) t_{t}-z_{t}^{C^{*}}\right],
\end{aligned}
$$

where $\kappa^{C^{*}}=\frac{\left(1-\theta_{C}^{*}\right)\left(1-\beta \theta_{C}^{*}\right)}{\theta_{C}^{*}}$, and

$$
\begin{aligned}
& \Delta p_{t}^{D^{*}}-\varphi_{D}^{*} \Delta p_{t-1}^{D^{*}} \\
& \quad=\beta E_{t}\left(\Delta p_{t+1}^{D^{*}}-\varphi_{D}^{*} \Delta p_{t}^{D^{*}}\right)+\kappa^{D^{*}}\left[\tilde{w}_{t}^{D^{*}}-q_{t}^{*}-z_{t}^{D^{*}}\right],
\end{aligned}
$$

where $\kappa^{D^{*}}=\frac{\left(1-\theta_{D}^{*}\right)\left(1-\beta \theta_{D}^{*}\right)}{\theta_{D}^{*}}$.

The market clearing conditions for the non-durable goods sector reads as follows:

$$
y_{t}^{C^{*}}=\tau^{*} c_{F, t}^{*}+\frac{n(1-\tau)}{1-n} c_{F, t} .
$$

Aggregate investment expenditures equal production of investment goods:

$$
y_{t}^{D^{*}}=\frac{\lambda \delta D^{*} i_{t}^{*}+(1-\lambda) \delta D^{B^{*}} i_{t}^{B^{*}}}{\lambda \delta D^{*}+(1-\lambda) \delta D^{B^{*}}}
$$

and the law of motion of the two types of housing stocks is given by

$$
\begin{aligned}
d_{t}^{*} & =(1-\delta) d_{t-1}^{*}+\delta i_{t-1}^{*}-\varepsilon_{t}^{A}, \\
d_{t}^{B^{*}} & =(1-\delta) d_{t-1}^{B^{*}}+\delta i_{t-1}^{B^{*}}-\varepsilon_{t}^{A} .
\end{aligned}
$$

Aggregated output is given by

$$
y_{t}^{*}=\alpha^{*} y_{t}^{C^{*}}+\left(1-\alpha^{*}\right)\left(y_{t}^{D^{*}}+q_{t}^{*}\right) .
$$


Euro-Area Variables and Other Equations

The relationship between the two nominal interest rates in the home and foreign country is as follows:

$$
r_{t}^{*}=r_{t}+\beta\left(\kappa_{b} b_{t}+\vartheta_{t}\right)
$$

The evolution of net foreign assets is

$$
\lambda b_{t}=\lambda \frac{1}{\beta} b_{t-1}+\frac{(1-n)\left(1-\tau^{*}\right)}{n}\left(c_{H, t}^{*}-t_{t}\right)-(1-\tau) c_{F, t},
$$

where we have used the fact that $t_{t}=-t_{t}^{*}$, and the evolution of the terms of trade is given by

$$
t_{t}=t_{t-1}+\Delta p_{t}^{F}-\Delta p_{t}^{H} .
$$

The monetary policy Taylor rule conducted by the ECB reads as follows:

$$
\begin{aligned}
r_{t}= & \gamma_{R} r_{t-1} \\
& +\left(1-\gamma_{R}\right)\left[\gamma_{\pi} \Delta p_{t}^{E M U}+\gamma_{\pi}\left(y_{t}^{E M U}-y_{t-1}^{E M U}+\varepsilon_{t}^{A}\right)\right]+\varepsilon_{t}^{m},
\end{aligned}
$$

where the euro-area CPI and output is given by

$$
\begin{aligned}
\Delta p_{t}^{E M U} & =n \Delta p_{t}^{C}+(1-n) \Delta p_{t}^{C^{*}}, \\
y_{t}^{E M U} & =n y_{t}+(1-n) y_{t}^{*} .
\end{aligned}
$$

Finally, in section 4, when we include the macroprudential tools, we assume that they are linear functions of an indicator variable $\left(\Upsilon_{t}\right.$ and $\left.\Upsilon_{t}^{*}\right)$ which is either credit growth or credit to GDP in each country:

$$
\begin{aligned}
\eta_{t} & =\gamma_{\eta} \Upsilon_{t} \\
\eta_{t}^{*} & =\gamma_{\eta} \Upsilon_{t}^{*}
\end{aligned}
$$


Shock Processes

All shocks included in the model evolve according to

$$
\begin{aligned}
\xi_{t}^{C} & =\rho_{\xi, H} \xi_{t-1}^{C}+\varepsilon_{t}^{\xi, C}, \\
\xi_{t}^{C^{*}} & =\rho_{\xi, H} \xi_{t-1}^{C^{*}}+\varepsilon_{t}^{\xi, C^{*}}, \\
\xi_{t}^{D} & =\rho_{\xi, D} \xi_{t-1}^{D}+\varepsilon_{t}^{\xi, D}+\varepsilon_{t}^{\xi, D, C O M}, \\
\xi_{t}^{D^{*}} & =\rho_{\xi, D} \xi_{t-1}^{D^{*}}+\varepsilon_{t}^{\xi, D^{*}}+\varepsilon_{t}^{\xi, D, C O M}, \\
z_{t}^{C} & =\rho_{Z, C} z_{t-1}^{C}+\varepsilon_{t}^{Z, C}+\varepsilon_{t}^{Z, C, C O M}, \\
z_{t}^{C^{*}} & =\rho_{Z, C} z_{t-1}^{C^{*}}+\varepsilon_{t}^{Z, C^{*}}+\varepsilon_{t}^{Z, C, C O M}, \\
z_{t}^{D} & =\rho_{Z, D} z_{t-1}^{D}+\varepsilon_{t}^{Z, D}, \\
z_{t}^{D^{*}} & =\rho_{Z, D} z_{t-1}^{D^{*}}+\varepsilon_{t}^{Z, D^{*}}, \\
\sigma_{\omega, t} & =\left(1-\rho_{\sigma \omega}\right) \bar{\sigma}_{\omega}+\rho_{\sigma \omega} \sigma_{\omega, t-1}+u_{\omega, t}, \\
\sigma_{\omega, t}^{*} & =\left(1-\rho_{\sigma \omega}\right) \bar{\sigma}_{\omega}+\rho_{\sigma \omega} \sigma_{\omega, t-1}^{*}+u_{\omega, t}^{*}, \\
\vartheta_{t} & =\rho_{\vartheta} \vartheta_{t-1}+\varepsilon_{t}^{\vartheta},
\end{aligned}
$$

while the non-stationary innovation to the union-wide technology shock and the monetary policy shock are i.i.d.: $\varepsilon_{t}^{A}$ and $\varepsilon_{t}^{m}$. 


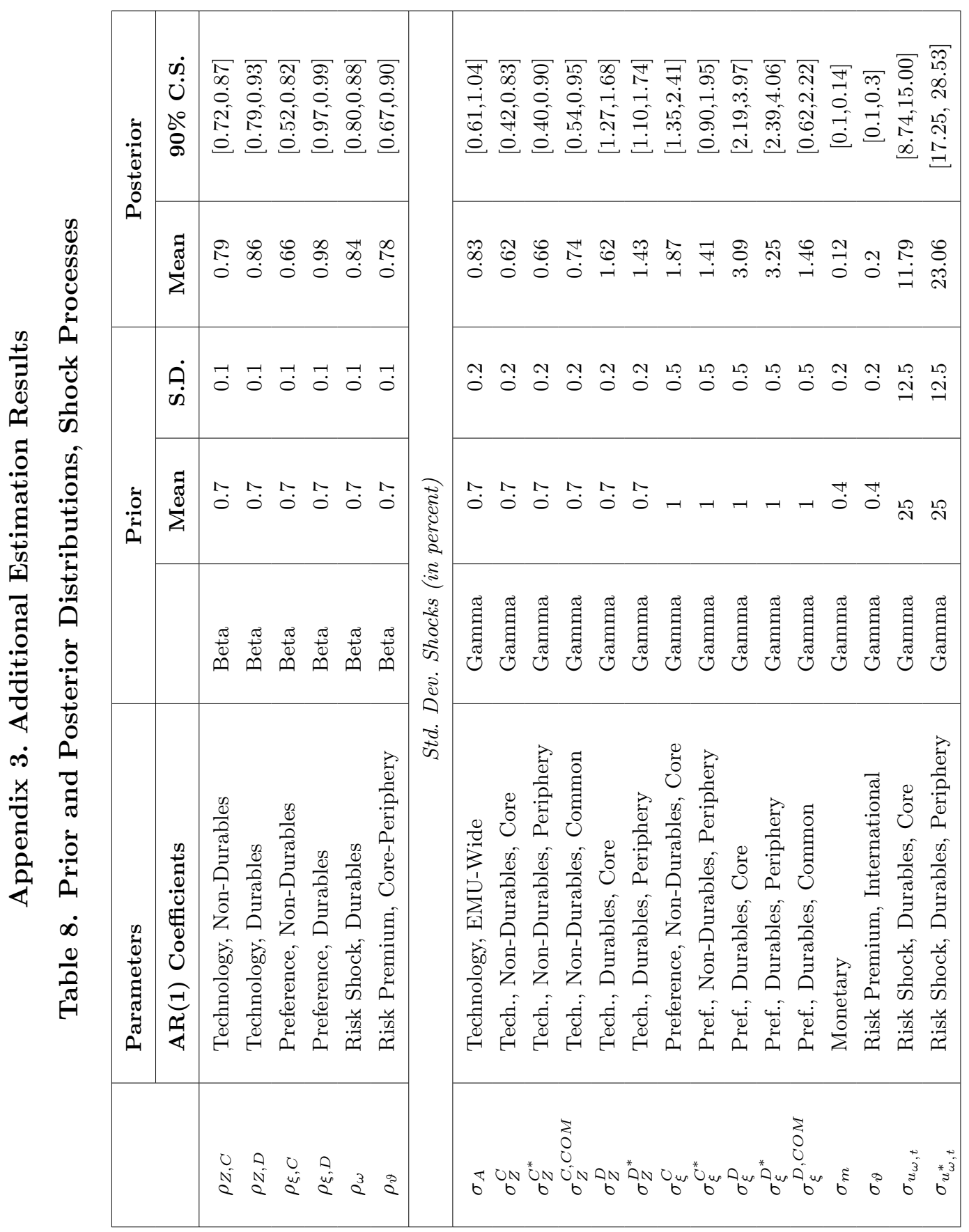




\begin{tabular}{|c|c|c|}
\hline$\stackrel{A}{8}_{4}^{*}$ & 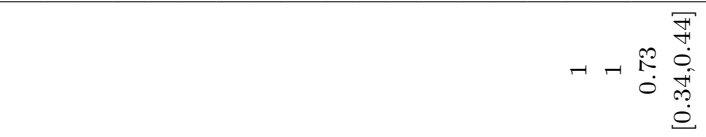 & 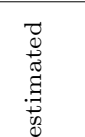 \\
\hline$\stackrel{A^{*}}{8}$ & 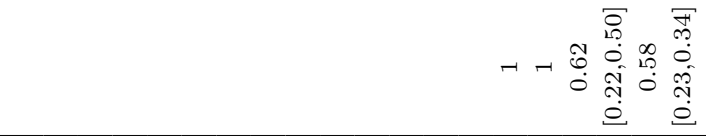 & 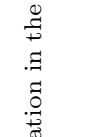 \\
\hline$\stackrel{*}{\mathrm{U}}$ & 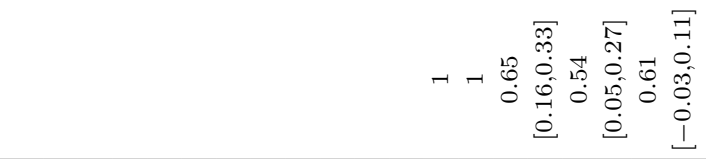 & 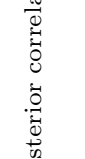 \\
\hline$\stackrel{0}{8}_{4}^{*}$ & 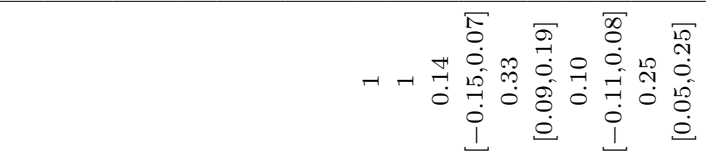 & 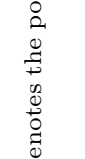 \\
\hline$\stackrel{\infty}{4}$ & 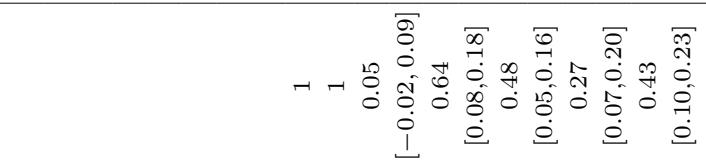 & $\begin{array}{l}7 \\
3 \\
0 \\
0 \\
0 \\
0 \\
+ \\
0 \\
0 \\
0\end{array}$ \\
\hline A & 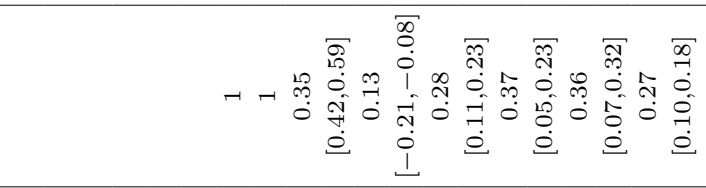 & 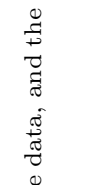 \\
\hline$\stackrel{8}{4}$ & 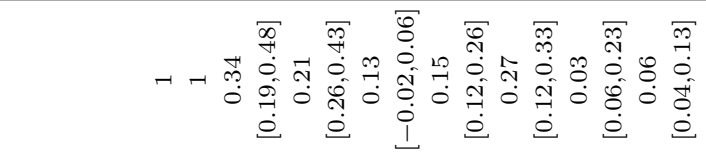 & 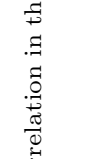 \\
\hline$\dot{y}$ & 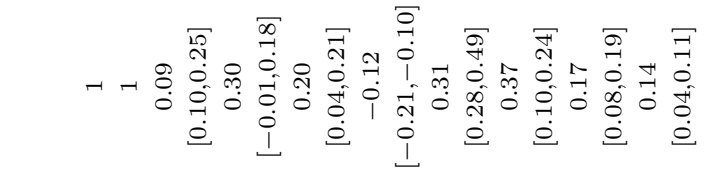 & 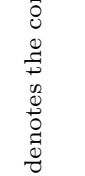 \\
\hline $\mathrm{O}_{4}^{8}$ & 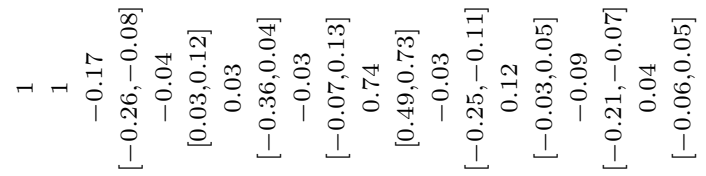 & 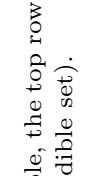 \\
\hline \& & 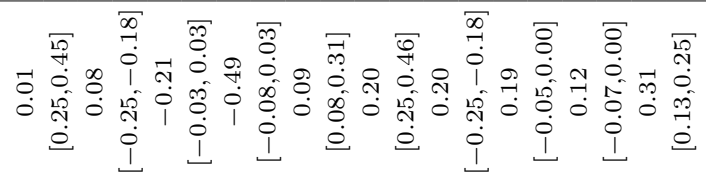 & 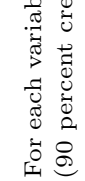 \\
\hline & 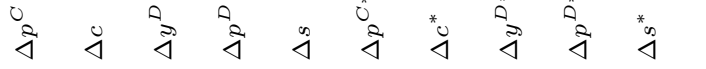 & \\
\hline
\end{tabular}




\section{Table 10. Posterior Variance Decomposition (90 percent confidence set)}

\begin{tabular}{|c|c|c|}
\hline & \multicolumn{2}{|c|}{ Shocks } \\
\hline$r$ & $\begin{array}{c}\text { Common Non-Durable Technology } \\
{[31.9,60.2]}\end{array}$ & $\begin{array}{c}\text { Core Non-Durable Technology } \\
\qquad[8.3,27.3]\end{array}$ \\
\hline$\Delta p^{C}$ & $\begin{array}{c}\text { Common Non-Durable Technology } \\
{[25.5,51.1]}\end{array}$ & $\begin{array}{c}\text { Core Non-Durable Technology } \\
\qquad[15.5,40.9]\end{array}$ \\
\hline$\Delta c$ & $\begin{array}{c}\text { Core Non-Durable Preference } \\
\qquad[48.5,71.6]\end{array}$ & $\begin{array}{c}\text { EMU-Wide Technology } \\
{[15.5,36.7]}\end{array}$ \\
\hline$\Delta y^{D}$ & $\begin{array}{l}\text { Core Durable Preference } \\
\qquad[31.2,60.3]\end{array}$ & $\begin{array}{c}\text { Core Durable Technology } \\
{[19.5,40.0]}\end{array}$ \\
\hline$\Delta p^{D}$ & $\begin{array}{c}\text { Core Durable Preference } \\
{[30.4,54.7]}\end{array}$ & $\begin{array}{c}\text { Core Durable Technology } \\
{[16.8,29.5]}\end{array}$ \\
\hline$\Delta s$ & $\begin{array}{l}\text { Risk Core } \\
{[34.9,59.8]}\end{array}$ & $\begin{array}{c}\text { Core Durable Preference } \\
\qquad[17.2,41.7]\end{array}$ \\
\hline$\Delta p^{C *}$ & $\begin{array}{c}\text { Common Non-Durable Technology } \\
{[19.2,39.6]}\end{array}$ & $\begin{array}{c}\text { Country Risk Premium } \\
{[13.8,36.8]}\end{array}$ \\
\hline$\Delta c^{*}$ & $\begin{array}{l}\text { Periphery Non-Durable Preference } \\
{[23.1,56.7]}\end{array}$ & $\begin{array}{c}\text { EMU-Wide Technology } \\
{[21.0,49.0]}\end{array}$ \\
\hline$\Delta y^{D *}$ & $\begin{array}{l}\text { Periphery Durable Preference } \\
\qquad[34.3,58.2]\end{array}$ & $\begin{array}{c}\text { Periphery Durable Technology } \\
{[19.4,33.3]}\end{array}$ \\
\hline$\Delta p^{D *}$ & $\begin{array}{l}\text { Periphery Durable Preference } \\
\qquad[31.5,61.2]\end{array}$ & $\begin{array}{c}\text { Periphery Durable Technology } \\
{[13.4,33.1]}\end{array}$ \\
\hline$\Delta s^{*}$ & $\begin{array}{l}\text { Risk Periphery } \\
\quad[62.3,81.8]\end{array}$ & $\begin{array}{c}\text { Periphery Durable Preference } \\
\qquad[8.9,19.6]\end{array}$ \\
\hline
\end{tabular}

\section{References}

Adolfson, M., S. Laseen, J. Lindé, and M. Villani. 2007. "Bayesian Estimation of an Open Economy DSGE Model with Incomplete Pass-Through." Journal of International Economics 72 (2): 481511.

An, S., and F. Schorfheide. 2007. "Bayesian Analysis of DSGE Models." Econometric Reviews 26 (2-4): 113-72.

Angelini, P., L. Clerc, V. Cúrdia, L. Gambacorta, A. Gerali, A. Locarno, R. Motto, W. Roeger, S. Van den Heuvel, and J. Vlcek. 2011. "Basel III: Long-Term Impact on Economic Performance and Fluctuations." BIS Working Paper No. 338. 
Angelini, P., S. Neri, and F. Panetta. 2011. "Monetary and Macroprudential Policies." Temi di discussione (Economic Working Paper) No. 801, Bank of Italy, Economic Research Department. Bank of England. 2009. "The Role of Macroprudential Policies." Discussion Paper.

Basel Committee on Banking Supervision. 2011. "Basel III: A Global Regulatory Framework for More Resilient Banks and Banking Systems." Bank for International Settlements.

Bean, C., M. Paustian, A. Penalver, and T. Taylor. 2010. "Monetary Policy after the Fall." Paper presented at the Federal Reserve Bank of Kansas City Annual Conference, Jackson Hole, Wyoming, September 16.

Beau, D., L. Clerc, and B. Mojon. 2012. "Macro-Prudential Policy and the Conduct of Monetary Policy." Working Paper No. 390, Banque de France.

Bernanke, B., M. Gertler, and S. Gilchrist. 1999. "The Financial Accelerator in a Quantitative Business Cycle Framework." In Handbook of Macroeconomics, Vol. 1C, ed. J. Taylor and M. Woodford, 1341-93. Elsevier.

Bianchi, J., and E. Mendoza. 2011. "Overborrowing, Financial Crises and 'Macro-prudential' Policy?" IMF Working Paper No. 11/24. Blanchard, O., G. Dell'Ariccia, and P. Mauro. 2010. "Rethinking Macroeconomic Policy." Journal of Money, Credit and Banking 42 (s1): 199-215.

Borio, C., and I. Shim. 2008. "What Can (Macro-)Prudential Policy Do to Support Monetary Policy?" BIS Working Paper No. 242. Brzoza-Brzezina, M., M. Kolasa, and K. Makarski. 2013. "Macroprudential Policy and Imbalances in the Euro Area." Working Paper No. 138, National Bank of Poland.

Calvo, G. 1983. "Staggered Prices in a Utility-Maximizing Framework." Journal of Monetary Economics 12 (3): 383-98.

Christiano, L., M. Eichenbaum, and C. Evans. 2005. "Nominal Rigidities and the Dynamic Effects of a Shock to Monetary Policy." Journal of Political Economy 113 (1): 1-45.

Christiano, L., R. Motto, and M. Rostagno. 2013. "Risk Shocks." NBER Working Paper No. 18682.

Claessens, S., A. Kose, and M. E. Terrones. 2009. "What Happens During Recessions, Crunches and Busts?" Economic Policy 24 (60): $653-700$. 
Collard, F., H. Dellas, B. Diba, and O. Loisel. 2013. "Optimal Monetary and Prudential Policies." Working Paper No. 413, Bank of France.

Crowe, C., G. Dell'Ariccia, D. Igan, and P. Rabanal. 2011. "How to Deal with Real Estate Booms: Lessons from Country Experiences." IMF Working Paper No. 11/91.

European Central Bank. 2009. "Housing Finance in the Euro Area." ECB Occasional Paper No. 101.

Fabiani, S., M. Druant, I. Hernando, C. Kwapil, B. Landau, C. Loupias, F. Martins, T. Mathä, R. Sabbatini, H. Stahl, and A. Stokman. 2006. "What Firms' Surveys Tell Us about Price-Setting Behavior in the Euro Area." International Journal of Central Banking 2 (3): 3-47.

Forlati, C., and L. Lambertini. 2011. "Risky Mortgages in a DSGE Model." International Journal of Central Banking 7 (1): 285336.

Galati, G., and R. Moessner. 2013. "Macroprudential Policy — A Literature Review." Journal of Economic Surveys 27 (5): 846-78.

Gerali, A., S. Neri, L. Sessa, and F. Signoretti. 2010. "Credit and Banking in a DSGE Model of the Euro Area." Journal of Money, Credit and Banking 42 (s1): 107-41.

Gertler, M., and P. Karadi. 2011. "A Model of Unconventional Monetary Policy." Journal of Monetary Economics 58 (1): 17-34.

Gruss, B., and S. Sgherri. 2009. "The Volatility Costs of Procyclical Lending Standards: An Assessment Using a DSGE Model." IMF Working Paper No. 09/35.

Iacoviello, M. 2005. "House Prices, Borrowing Constraints, and Monetary Policy in the Business Cycle." American Economic Review 95 (3): 739-64.

Iacoviello M., and S. Neri. 2010. "Housing Market Spillovers: Evidence from an Estimated DSGE Model." American Economic Journal: Macroeconomics 2 (2): 125-64.

International Monetary Fund. 2009. "Lessons for Monetary Policy from Asset Price Fluctuations." World Economic Outlook (October): 93-120 (chapter 3).

- 2012. "Dealing with Household Debt." World Economic Outlook (April): 89-124 (chapter 3).

Kaminsky, G., and C. M. Reinhart. 1999. "The Twin Crises: The Causes of Banking and Balance-of-Payments Problems." American Economic Review 89 (3): 473-500. 
Kannan, P., P. Rabanal, and A. Scott. 2012. "Monetary and Macroprudential Policy Rules in a Model with House Price Booms." The B.E. Journal of Macroeconomics 12 (1): 1-44.

Lambertini, L., C. Mendicino, and M. T. Punzi. 2013. "Leaning Against Boom-Bust Cycles in Credit and Housing Prices: Monetary and Macroprudential Policy." Journal of Economic Dynamics and Control 37 (8): 1500-1522.

Macroeconomic Assessment Group (MAG). 2010a. "Assessing the Macroeconomic Impact of the Transition to Stronger Capital and Liquidity Requirements - Interim Report." Group established by the Financial Stability Board and the Basel Committee on Banking Supervision (August).

. 2010b. "Assessing the Macroeconomic Impact of the Transition to Stronger Capital and Liquidity Requirements-Final Report." Group established by the Financial Stability Board and the Basel Committee on Banking Supervision (December).

Medina, J. P., and J. Roldós. 2014. "Monetary and Macroprudential Policies to Manage Capital Flows." IMF Working Paper No. 14/30 (February).

Mortgage Bankers Association. 2008. "Lenders' Cost of Foreclosure." Policy Paper, Congressional Education Series Briefing, May 28. Roger, S., and J. Vlcek. 2011. "Macroeconomic Costs of Higher Bank Capital and Liquidity Requirements." IMF Working Paper No. $11 / 103$.

Rubio, M. 2013. "Macroprudential Policy Implementation in a Heterogeneous Monetary Union." Mimeo, University of Nottingham.

Schmitt-Grohé, S., and M. Uribe. 2003. "Closing Small Open Economy Models." Journal of International Economics 61 (1): 16385.

. 2007. "Optimal Simple and Implementable Monetary and Fiscal Rules." Journal of Monetary Economics 54 (6): 1702-25. Smets, F., and R. Wouters. 2003. "An Estimated Dynamic Stochastic General Equilibrium Model of the Euro Area." Journal of the European Economic Association 1 (5): 1123-75.

Sørensen, C., and J. Lichtenberger. 2007. "Mortgage Interest Rate Dispersion in the Euro Area." ECB Working Paper No. 733.

Suh, H. 2012. "Macroprudential Policy: Its Effects and Relationship to Monetary Policy." Working Paper No. 12-28, Federal Reserve Bank of Philadelphia. 
Svensson, L. 2012. "Comment on Michael Woodford: 'Inflation Targeting and Financial Stability'." Economic Review (Sveriges Riksbank) 1: 33-39.

Unsal, F. 2013. "Capital Flows and Financial Stability: Monetary Policy and Macroprudential Responses." International Journal of Central Banking 9 (1): 233-85.

Vandenbussche, J., U. Vogel, and E. Detragiache. 2012. "Macroprudential Policies and Housing Prices-A New Database and Empirical Evidence for Central, Eastern, and Southeastern Europe." IMF Working Paper No. 12/303.

Zhang, L. 2009. "Bank Capital Regulation, the Lending Channel and Business Cycles." Discussion Paper Series 1: Economic Studies No. 2009,33, Deutsche Bundesbank, Research Centre. 